\title{
Single Event Kinetic Modelling without Explicit Generation of Large Networks: Application to Hydrocracking of Long Paraffins
}

\author{
D. Guillaume ${ }^{1 *}$, E. Valéry ${ }^{1}$, J.J. Verstraete ${ }^{1}$, K. Surla ${ }^{1}$, P. Galtier ${ }^{1}$ and D. Schweich ${ }^{2}$ \\ 1 IFP Energies nouvelles, Rond-point de l'échangeur de Solaize, BP 3, 69360 Solaize - France \\ 2 LGPC, ESCPE-CNRS, 43 bd du 11 novembre 1918, BP 2077, 69616 Villeurbanne - France \\ $\S$ Current address: Novasep, Pompey - France \\ denis.guillaume@ifpen.fr - eric_valery@novasep.com - jan.verstraete@ifpen.fr - karine.surla@ifpen.fr - pierre.galtier@ifpen.fr - dsw@lgpc.cpe.fr \\ * Corresponding author
}

Résumé - Modélisation cinétique par événements constitutifs sans génération explicite de grands réseaux : application à l'hydrocraquage des paraffines longues - Le concept de modélisation par événements constitutifs permet de développer des modèles cinétiques pour la simulation des procédés de raffinage. Pour des réseaux réactionnels de centaines de milliers d'espèces, comme cela est le cas pour le reformage catalytique, le regroupement rigoureux par nombre d'atomes de carbone et degré de ramification a été utilisé efficacement en faisant l'hypothèse de l'équilibre chimique dans chaque groupe. Cette technique de regroupement conduit à un modèle regroupé compact sans perte d'information, mais nécessite tous les détails d'un réseau réactionnel complet, généré de manière explicite.

Les techniques classiques de génération de réseaux deviennent inutilisables quand les hydrocarbures contiennent au delà d'environ 20 atomes de carbone à cause de la croissance extrêmement rapide du réseau réactionnel. Ainsi, des techniques implicites de regroupement ont été développées afin de calculer les coefficients de regroupement sans avoir à générer le réseau réactionnel détaillé. Deux approches alternatives et équivalentes sont présentées, basées soit sur une décomposition en classes structurales, soit une décomposition en chaînes latérales. Ces deux méthodes sont comparées et la méthode de décomposition en chaînes latérales est appliquée à la modélisation cinétique de l'hydrocraquage des paraffines longues. La méthode de décomposition en chaînes latérales est strictement équivalente à la méthode originelle basée sur la génération explicite du réseau réactionnel détaillé, pour autant que la méthode de contribution de groupe de Benson soit utilisée pour calculer les propriétés thermodynamiques dans chacune des approches.

\footnotetext{
Abstract - Single Event Kinetic Modelling without Explicit Generation of Large Networks: Application to Hydrocracking of Long Paraffins - The single event modelling concept allows developing kinetic models for the simulation of refinery processes. For reaction networks with several hundreds of thousands of species, as is the case for catalytic reforming, rigorous relumping by carbon atom number and branching degree were efficiently employed by assuming chemical equilibrium in each lump. This relumping technique yields a compact lumped model without any loss of information, but requires the full detail of an explicitly generated reaction network.

Classic network generation techniques become impractical when the hydrocarbon species contain more than approximately 20 carbon atoms, because of the extremely rapid growth of reaction network. Hence,
} 
implicit relumping techniques were developed in order to compute lumping coefficients without generating the detailed reaction network. Two alternative and equivalent approaches are presented, based either on structural classes or on lateral chain decomposition. These two methods are discussed and the lateral chain decomposition method is applied to the kinetic modelling of long chain paraffin hydroisomerization and hydrocracking. The lateral chain decomposition technique is exactly equivalent to the original calculation method based on the explicitly generated detailed reaction network, as long as Benson's group contribution method is used to calculate the necessary thermodynamic data in both approaches.

\section{NOMENCLATURE}

\section{Roman}

$b_{F_{o}} \quad$ Physisorption coefficient for lump $F_{o}$

$b_{P_{i}} \quad$ Physisorption coefficient for paraffin $P_{i}$

$C_{\text {sat }} \quad$ Saturation concentration, i.e. physical adsorption capacity of the zeolite

$C_{H^{*}} \quad$ Concentration of free acid sites

$C_{t} \quad$ Total concentration of acid sites

$D E N^{g} \quad$ Langmuir type inhibition term due to physical adsorption for the zeolite

$D E N_{\text {acid }}^{g} \quad$ Langmuir type inhibition term due to chemisorption on the acid sites

$F_{o} \quad$ Reacting paraffin lump

$F_{p}, F_{q} \quad$ Produced paraffin lumps

$K_{D H_{i j}} \quad$ Dehydrogenation/hydrogenation equilibrium constant of paraffin $P_{i}$ into olefin $O_{i j}$

$\widetilde{K}_{\text {isom }} \quad$ Intrinsic equilibrium constant of olefin isomerization (excluding the contributions for rotation symmetries and chirality)

$K_{\mathrm{Pr}}\left(m ; O_{i j}\right)$ Protonation/deprotonation equilibrium constant for a carbenium ion of type $m$ into olefin $O_{i j}$

$\tilde{K}_{\mathrm{Pr}} \quad$ Intrinsic equilibrium constant of olefin protonation (excluding the contributions for rotation symmetries and chirality)

$K_{g}^{*}(n, T) \quad$ Equilibrium coefficient of formation of the paraffin lump $g$ at temperature $T$

$K_{\text {ref,g }}^{*}(n, T) \quad$ Intrinsic equilibrium coefficient of formation of reference olefin $O_{r e f}$ and of hydrogen from the pure elements at temperature $T$

$k_{c r} \quad$ Cracking rate coefficient

$k_{p c p} \quad$ PCP branching rate coefficient

$k_{X} \quad$ Rate coefficient for the elementary step for reaction $X(X=r e a c, P r$, dep,$\ldots)$

$\tilde{k}_{X} \quad$ Single event rate coefficient for reaction $X$ $(X=r e a c, P r$, dep,$\ldots)$

$k_{\text {reac }}(m ; n)$ Rate coefficient for reaction reac of a carbenium ion of type $m$ into a carbenium ion of type $n$

$k_{\text {reac }}^{*}(m ; u)$ Re-parameterised composite rate coefficient for reaction reac of a carbenium ion of type $m$ into a carbenium ion of type $n$
$L C_{\text {isom }(m, n)}(g, h)$ Lumping coefficient for isomerization of lump $g$ into lump $h$ by means of a $(m, n)$ type isomerization.

\section{LHSV Liquid Hourly Space Velocity}

$m$

$N_{i \operatorname{som}(m, n)}$

$n$

Type (primary, secondary, tertiary) of the reactive carbenium ion

Number of $(m, n)$ type pathways that allow to transform lump $g$ into lump $h$

Type (primary, secondary, tertiary) of the produced carbenium ion

Number of branches

Number of carbon atoms

Number of chiral carbon atoms among the three carbon atoms of the 2-electron 3-center bond

\section{$n_{e} \quad$ Number of single events}

$n_{p}$

$n_{a l k, C}$

$n_{\text {ions }, C}$

Number of carbon atoms in the "main chain" of a lateral chain

Number of alkanes in the structural class $C$

Number of carbenium ions in the carbenium ion structural class $C$

$n_{\text {gch, },}$

$n_{p, C}$

$n_{s, C}$

$n_{t, C}$

$n_{q, C}$

$n_{\text {occ }(A-Z A-B)}$

$O_{i j}$

$O_{\text {ref }}$

$P_{i}$

$P_{F_{o}}$

$P_{\mathrm{H}_{2}}$

$P_{P_{i}}$

$r\left\{\begin{array}{l}\operatorname{reac}(m, u) \\ F_{o} \rightarrow F_{p}\end{array}\right\}$
Minimum number of gauche interactions for paraffins in structural class $C$

Number of primary carbon atoms for paraffins in structural class $C$

Number of secondary carbon atoms for paraffins in structural class $C$

Number of tertiary carbon atoms for paraffins in structural class $C$

Number of quaternary carbon atoms for paraffins in structural class $C$

Number of reactions of type $(m, u)$ that involve activated complex $A-Z A-B$

Olefin $j$ resulting from the dehydrogenation of paraffin $P_{i}$

Reference olefin

Paraffin $i$

Partial pressure of lump $F_{o}$

Partial pressure of hydrogen

Partial pressure of paraffin $P_{i}$

Rate of reaction reac, of type $(m, u)$, between lump $F_{o}$ and lump $F_{p}$ 


\begin{tabular}{|c|c|}
\hline$R$ & Ideal gas constant \\
\hline$R_{i k}^{+}$ & $\begin{array}{l}\text { Carbenium ion } k \text { resulting from protonation of } \\
\text { olefin } O_{i j}\end{array}$ \\
\hline $\operatorname{SPLC}\left(n_{c}, n_{b}\right)$ & $\begin{array}{l}\text { Symmetry Property of Lateral Chains with } n_{c} \\
\text { carbon atoms and } n_{b} \text { branches }\end{array}$ \\
\hline $\operatorname{TPLC}\left(n_{c}, n_{b}\right)$ & $\begin{array}{l}\text { Thermodynamic Property of Lateral Chains } \\
\text { with } n_{c} \text { carbon atoms and } n_{b} \text { branches }\end{array}$ \\
\hline$T$ & Temperature \\
\hline$W$ & Weight of catalyst inside the reactor \\
\hline$W / F_{t o t}^{0}$ & Space time \\
\hline Y & Species $\left(Y=\mathrm{H}_{2}, P_{i}, O_{i j}, R_{i k}^{+}, \#_{i k l}, \ldots\right)$ \\
\hline$y_{i}$ & Mole fraction of paraffin $P_{i}$ in lump $F_{o}$ \\
\hline$y_{i}$ & Experimental mole fraction of observable $i$ \\
\hline$\hat{y}_{i}$ & Calculated mole fraction of observable $i$ \\
\hline$Z$ & $\begin{array}{l}\text { Group of Benson's group contribution method } \\
\text { (primary carbon atom, secondary carbon atom, } \\
\text { tertiary carbon atom, quaternary carbon atom, } \\
\text { and minimum number of gauche interactions) }\end{array}$ \\
\hline
\end{tabular}

\section{Greek}

$\Delta G_{f}^{0}(Y)$

$\Delta \widetilde{G}_{f}^{0}(Y)$

$\Delta \widetilde{G}_{f, Z}^{0}$

$\sigma_{Y}$

$\sigma_{P_{i}, C}$

\section{Subscript}

ext

int

$i$

$i j$

$i k$

$i k l$

$r$

reac

\#
Gibbs free enthalpy of formation of species $Y$

Intrinsic Gibbs free enthalpy of formation (rotation symmetries and chirality excluded)

Benson group contribution to the intrinsic Gibbs free enthalpy of formation (rotation symmetries and chirality excluded) at temperature $T$ for group $Z$

Global symmetry number of species $Y$

Global symmetry number for paraffins $P_{i}$ in the structural class $C$

Refers to the external symmetry

Refers to the internal symmetry

Refers to paraffin $P_{i}$ in lump $F_{o}$

Refers to the $j$-th olefin $O_{i j}$ resulting from dehydrogenation of paraffin $P_{i}$

Refers to the $k$-th carbenium ion $R_{i k}^{+}$resulting from protonation of olefin $O_{i j}$

Refers to the $l$-th activated complex $\#_{i k l}$ resulting from a reaction of carbenium ion $R_{i k}^{+}$

Reactant

Type of reaction (PCP branching, methyl shift, ...)

Activated complex

\section{INTRODUCTION}

Using the concept of "single events" is an efficient way of modelling acid-catalyzed reactions in refining without introducing reductive assumptions on the composition of the feed (Froment, 1999, 2005). The single event methodology has already been extensively described in the literature. This acid-catalyzed modelling approach has been applied to isomerization (Guillaume et al., 2003a; Surla et al., 2004, 2011), alkylation (Martinis and Froment, 2006), olefin oligomerization (Guillaume, 2006; Shahrouzi et al., 2008), methanol-to-olefins (Park and Froment, 2001a,b, 2004; Al Wahabi and Froment, 2004; Froment, 2005), catalytic reforming (Sotelo-Boyás and Froment, 2009; Cochegrue et al., 2011), catalytic cracking (Feng et al., 1993; Dewachtere et al., 1999; Beirnaert et al., 2001; Moustafa and Froment, 2003; Froment, 2005; Quintana-Solórzano et al., 2005, 2007a, b, 2010) and hydrocracking (Baltanas and Froment, 1985; Baltanas et al., 1989; Vynckier and Froment, 1991; Svoboda et al., 1995; Schweitzer et al., 1999; Martens and Froment, 1999; Martens et al., 2000, 2001; Martens and Marin, 2001; Thybaut et al., 2001, 2009; Thybaut and Marin, 2003; Laxmi Narasimhan et al., 2003a, b, 2004, 2006, 2007; Chavarría-Hernández et al., 2004, 2008; Kumar and Froment, 2007a, b; Chavarría-Hernández and Ramírez, 2009; Mitsios et al., 2009; Choudhury et al., 2010).

Concerning the modelling of the hydrocracking process, good results have been obtained for the modelling of hydrocracking at lab scale (Baltanas et al., 1989; Vynckier and Froment, 1991; Svoboda et al., 1995; Martens and Froment, 1999; Martens and Marin, 2001; Martens et al., 2001; Thybaut and Marin, 2003; Kumar and Froment, 2007a, b; Chavarría-Hernández et al., 2008; Chavarría-Hernández and Ramírez, 2009; Thybaut et al., 2009) and at pilot plant scale (Schweitzer et al., 1999; Mitsios et al., 2009). The direct approach of the methodology, as described by Baltanas and Froment (1985) and Vynckier and Froment (1991), becomes unpractical when it is applied to heavy feeds with high carbon numbers, as the size of the generated network, both in terms of species and reactions, increases extremely rapidly with carbon number, resulting in colossal computing times and intractable networks. Despite this, Kumar and Froment $(2007 a, b)$ were able to apply the direct generation of the entire detailed reaction network up to $\mathrm{C}_{40}$ by using dynamic memory allocation via linked lists for storing and searching the intermediate olefinic and ionic species. While the continuously developing computing power and memory availability will allow to push back the limits of the network size attainable by direct generation, this approach will still remain a complex and lengthy task.

In order to circumvent this difficulty, the equations derived for the single event kinetic modelling method were carefully inspected. Their reformulation led to two alternative methods: one based upon the concept of structural classes 
(Martens, 2000; Martens and Marin, 2001; Laxmi Narasimhan et al., 2004), the other based upon the concept of lateral chains (Valéry, 2002; Guillaume et al., 2003b; Valéry et al., 2007; Mitsios et al., 2009). Both methods allow to circumvent the explicit generation of the detailed reaction network. Moreover, they also provide further in the evolution of the reaction network with carbon number.

The method proposed by Martens and Marin (2001), based on structural classes, essentially consists in counting structures that have the same branching number and global symmetry so as to determine the frequency of each structure by carbon number and by degree of branching. In this way, this method does not need any explicit network generation. For a given network, the structural classes have to be enumerated by the user. Hence, this method seems to need a classification of the structural classes, which has to be manually updated when the maximum degree of branching of the network is increased.

The method developed by Valéry (2002) is based on a lateral chain decomposition approach. The computations are entirely automated. As only input, the highest carbon number and the highest degree of branching in the network has to be specified by the user (Valéry et al., 2007; Mitsios et al., 2009).

It should be stressed that both techniques are strictly equivalent and the lumping coefficients they calculate will have the same value. Moreover, both methods are strictly equivalent to the original calculation method based on the explicitly generated reaction network, as long as Benson's group contribution method (Benson et al., 1969; Benson, 1976) is used to obtain the necessary thermodynamic data in all approaches. Of the two alternative methods that do not need the explicit network generation, the lateral chain decomposition method seems easier to apply, however. In this paper, this lateral chain decomposition approach is used to calculate these lumping coefficients, which are then subsequently used to derive a kinetic model for long paraffin hydrocracking. The kinetic parameters were identified based on $n$-hexadecane hydrocracking data. Validation is performed by extrapolating the single event kinetic model to higher carbon number paraffins and confronting the model results to experimental data.

\section{A POSTERIORI RELUMPING OF LARGE NETWORKS}

The use of computer tools is the route for modelling very large reaction networks. As illustrated in the previous papers, the single event modelling methodology is based on three main tools and concepts:

- computer generation of the reaction network (to obtain the full mechanistic detail);

- single event rate coefficients (to reduce the number of kinetic parameters);
- rigorous regrouping (to limit the number of species without losing information).

This methodology, as initially developed (Baltanas and Froment, 1985; Vynckier and Froment, 1991), is not really efficient for extremely large networks as those needed to describe hydrocracking of actual VGO feedstocks. However, alternative rigorous solutions can be developed, as described in Martens (2000) and Valéry (2002). Both solutions are based on reformulating the kinetic equations and on examining them from a new perspective. Let us first examine the solutions from the original equations.

According to Baltanas and Froment (1985), the rate coefficient of an elementary step can be written as:

$$
k_{\text {reac }}(m, n)=n_{e} \cdot \tilde{k}_{\text {reac }}(m, n)
$$

where reac stands for the type of reaction (PCP branching / methyl shift / ...), $n_{e}$ is the number of single events, $m$ and $n$ characterize the nature of the reactive carbenium ion and of the produced carbenium ion. It is assumed that the intrinsic parameter $\widetilde{K}_{\text {reac }}(m, n)$ does not depend on the number of carbon atoms but only on the type of the reaction and on the type of reactive and produced carbenium ions. The influence of the geometry of the molecules is limited to the number of single events, which is equal to $n_{e}=\frac{\sigma_{r}}{\sigma_{\#}}$, i.e. the ratio of the symmetry number of the reactive ion and of the activated complex involved in the reaction. The single event concept allows to drastically reduce the number of rate coefficients entailed in the kinetic description of the full network.

Vynckier and Froment (1991) introduced a posteriori lumping of species by carbon number and by degree of branching in large single event networks. In opposition to $a$ priori lumping technique, which is generally a "blind" lumping approach devised to cope with the lack of componentbased analytical data, this a posteriori lumping scheme is a rigorous relumping approach based on regrouping species at thermodynamic equilibrium inside a single lump. In this sense, it is strictly an exact lumping technique as defined by Wei and Kuo (1969), since the composition is known through the equilibrium relations. The latter underlying assumption was reasonably verified by Schweitzer et al. (1999) and Valéry (2002) for the hydrocracking of $n$-hexadecane.

The main assumptions in the relumping scheme are:

- hydrogenation/dehydrogenation steps are at equilibrium;

- protonation/deprotonation steps are at equilibrium;

- intermediate species (alkenes, carbenium ions) are at pseudo-steady state;

- the adsorption coefficients for physical (Langmuir) adsorption depend only on the number of carbon atoms of the molecules;

- the amount of adsorbed olefins is negligible with respect to the amount of paraffins. 
The second assumption (protonation/deprotonation at equilibrium) also implies that the hydride shift reactions between carbenium ions are also at equilibrium. It is further assumed that gas-liquid equilibrium prevails. The latter hypothesis enables expressing the rate laws using the partial pressures instead of the concentrations of the dissolved species (Martens and Marin, 2001).

Let $F_{o}, F_{p}$ and $F_{q}$ be lumps, i.e. groups of paraffins. In each lump, all hydrocarbons have the same number of carbon atoms and they are in chemical equilibrium. Let "reac" be an elementary step, such as a PCP or PCB isomerization step $\left(F_{o} \rightarrow F_{p}\right)$, or a $\beta$-scission cracking step $\left(F_{o} \rightarrow F_{p}+F_{q}\right)$. The lumped rate expression for the disappearance of lump $F_{o}$ is given by (Vynckier and Froment, 1991):

$$
\begin{aligned}
& r_{\{\operatorname{reac}(m, u)}\left\{\begin{array}{l}
\left.F_{o} \rightarrow F_{p}\left(+F_{q}\right)\right\} \\
=
\end{array}\right. \\
& \sum_{i k l \in\left\{\begin{array}{l}
\text { reac }(m, u) \\
F_{o} \rightarrow F_{p}\left(+F_{q}\right)
\end{array}\right\}}\left[K_{\operatorname{Pr}}\left(m ; O_{i j}\right) \cdot K_{D H_{i j}} \cdot k_{\text {reac }}(m ; u) \cdot y_{i}\right] . \\
& \frac{C_{t} \cdot C_{s a t} \cdot b_{F_{o}} \cdot P_{F_{o}}}{P_{\mathrm{H}_{2}} \cdot D E N^{g}+D E N_{\text {acid }}^{g}}
\end{aligned}
$$

where $P_{\mathrm{H}_{2}} \quad$ is the partial pressure of hydrogen,

$P_{F_{0}} \quad$ is the partial pressure of lump $F_{o}$,

$b_{F_{0}} \quad$ is the physical adsorption coefficient of lump $F_{o}$,

$C_{\text {sat }} \quad$ is the physical adsorption capacity of the zeolite (assumed to be lump independent),

$C_{t} \quad$ is the total concentration of acid sites,

$D E N^{g} \quad$ is the inhibition term due to physical adsorption for the zeolite,

$D E N_{a c i d}^{g}$ is the inhibition term due to chemisorption on the acid sites, i.e. protonation of olefins,

$y_{i} \quad$ is the mole fraction of paraffin $P_{i}$ in lump $F_{o}$, $m, u \quad$ are the type (secondary or tertiary) of the reactant and product carbenium ions,

$k_{\text {reac }}(m ; n)$ is the rate coefficient for reaction reac of a carbenium ion of type $m$ into a carbenium ion of type $n$,

$K_{D H_{i j}} \quad$ is the dehydrogenation/hydrogenation equilibrium constant of paraffin $P_{i}$ into olefin $O_{i j}$,

$K_{\mathrm{Pr}}\left(m ; O_{i j}\right)$ is the protonation/deprotonation equilibrium constant for a carbenium ion of type $m$ into olefin $O_{i j}$.

Index " $i$ " refers to paraffin $P_{i}$ in $F_{o}$, " $i j$ " to the $j$-th olefin $O_{i j}$ resulting from dehydrogenation of paraffin $P_{i}$, "ik" to the $k$-th carbenium ion $R_{i k}^{+}$resulting from protonation of olefin $O_{i j}$, and " $i k l$ " to the $l$-th activated complex $\#_{i k l}$ resulting from a reaction of carbenium ion $R_{i k}^{+}$(Fig. 1). Paraffin " $i$ ", olefin " $i j$ ", carbenium ion " $i k$ ", and activated complex "ikl" have the same number of carbon atoms within lump $F_{o}$.
For the three rate coefficients, the following relations apply:

$$
\begin{gathered}
k_{\text {reac }}(m, u)=n_{e} \cdot \tilde{k}_{\text {reac }}(m, u)=\frac{\sigma_{R_{i k}^{+}}}{\sigma_{\#_{i k l}}} \cdot \tilde{k}_{\text {reac }}(m, u) \\
K_{\mathrm{Pr}}\left(m, O_{i j}\right)=\frac{\sigma_{O_{i j}}}{\sigma_{R_{i k}^{+}}} \cdot \tilde{K}_{\mathrm{Pr}}\left(m, O_{i j}\right) \\
\tilde{K}_{\mathrm{Pr}}\left(m, O_{i j}\right)=\tilde{K}_{\mathrm{Pr}}\left(m, O_{r e f}\right) \cdot \tilde{K}_{i s o m}\left(O_{i j} \Leftrightarrow O_{r e f}\right)= \\
\tilde{K}_{\mathrm{Pr}}\left(m, O_{r e f}\right) \cdot e^{\left(-\frac{\Delta \tilde{G}_{f}^{o}\left(O_{r e f}\right)-\Delta \tilde{G}_{f}^{\circ}\left(O_{i j}\right)}{R T}\right)} \\
e^{\left(-\frac{\Delta \tilde{G}_{f}^{\circ}\left(O_{i j}\right)}{R T}\right)}=\sigma_{O_{i j}} \cdot e^{\left(-\frac{\Delta G_{f}^{\circ}\left(O_{i j}\right)}{R T}\right)}
\end{gathered}
$$

where $k_{X}$

$\tilde{k}_{X}$

is the rate coefficient for the elementary step for reaction $X(X=r e a c, P r$, dep,$\ldots)$,

$\tilde{k}_{X} \quad$ is the single event rate coefficient for reaction $X$,

$\sigma_{Y} \quad$ is the global symmetry number of species $Y$ $\left(Y=O_{i j}, R_{i k}^{+}, \#_{i k l}, \ldots\right)$,

$\tilde{K}_{\text {isom }} \quad$ is the intrinsic equilibrium constant of olefin isomerization (excluding the contributions for rotation symmetries and chirality),

$\tilde{K}_{\mathrm{Pr}} \quad$ is the intrinsic equilibrium constant of olefin protonation (excluding the contributions for rotation symmetries and chirality),

$\Delta G_{f}^{0}(Y)$ is the Gibbs free enthalpy of formation of species $Y$,

$\Delta \widetilde{G}_{f}^{0}(Y)$ is the intrinsic Gibbs free enthalpy of formation (rotation symmetries and chirality excluded).

The two inhibition terms combine the contributions of the adsorption of the various species:

$$
\begin{aligned}
& D E N^{g}=1+\sum_{q} b_{F_{q}} P_{F_{q}} \\
& D E N_{\text {acid }}^{g}=\sum_{\forall i o n} C_{s a t} \cdot b_{P_{i}} \cdot K_{D H_{i j}}\left(P_{i} \Leftrightarrow O_{i j}+\mathrm{H}_{2}\right) \cdot \\
& \tilde{K}_{\text {isom }}\left(O_{i j} \Leftrightarrow O_{r e f}\right) \cdot \frac{\sigma_{O_{r e f}}}{\sigma_{R_{i k}^{+}}} \cdot \tilde{K}_{\operatorname{Pr}}\left(m, O_{r e f}\right) \cdot P_{P_{i}}
\end{aligned}
$$

where $P_{F_{q}}$ is the partial pressure of lump $F_{q}$,

$P_{P_{i}}$ is the partial pressure of paraffin $P_{i}$,

$b_{P_{i}}$ is the physical adsorption constant of paraffin $P_{i}$.

The mole fraction of paraffin $P_{i}$ in lump $F_{o}$ is given by:

$$
y_{i}=\frac{e^{\left(-\frac{\Delta G_{f}^{\circ}\left(P_{i}\right)}{R T}\right)}}{\sum_{P_{i} \in F_{o}} e^{\left(-\frac{\Delta G_{f}^{\circ}\left(P_{i}\right)}{R T}\right)}}
$$




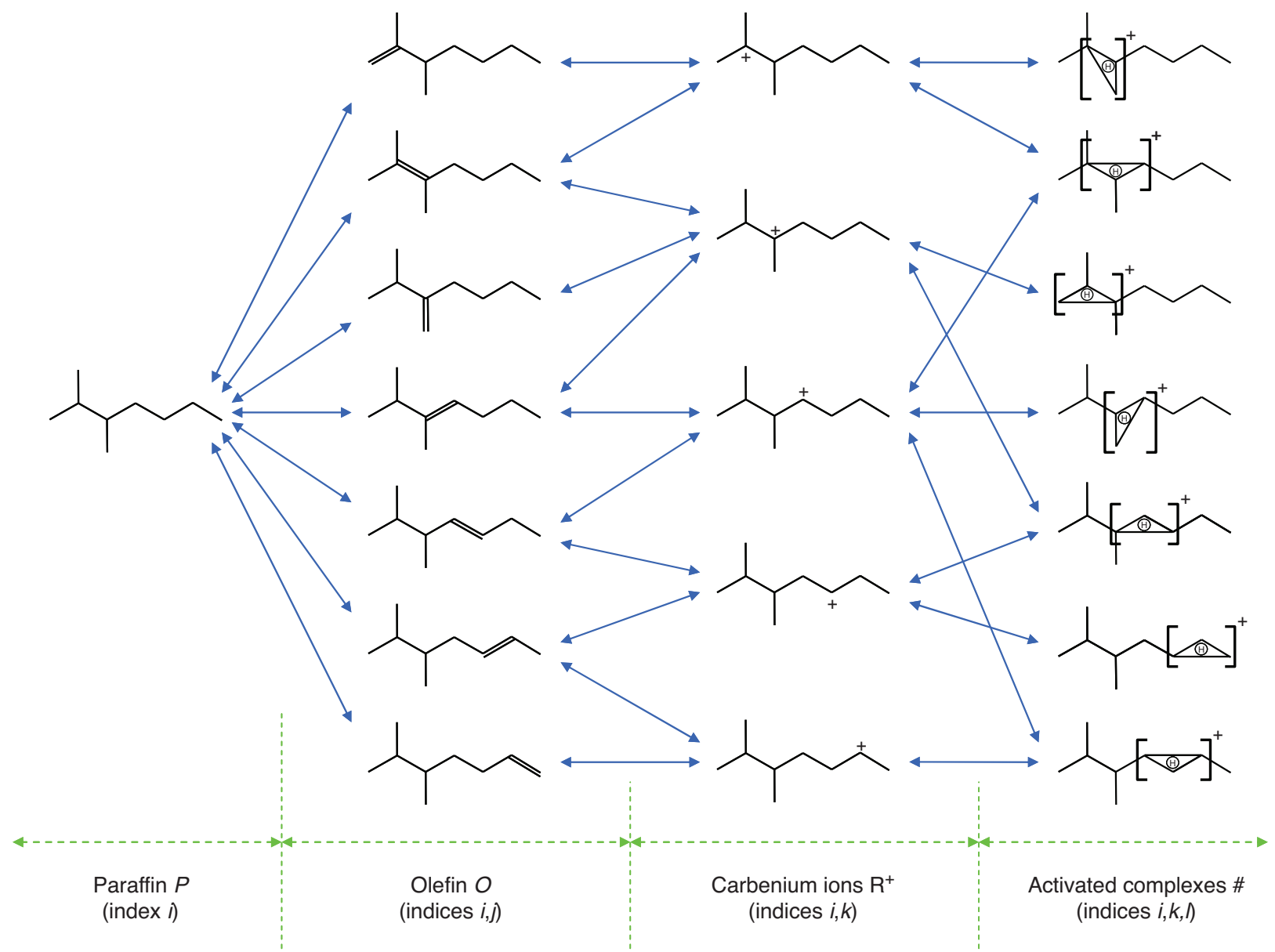

Figure 1

Definitions of the symbols and indices of paraffins, olefins and activated complexes illustrated for 2,3 dimethyl heptane structures.

Finally, the equilibrium constant for dehydrogenation of paraffin $P_{i}$ into olefin $O_{i j}$ can be calculated from the Gibbs free energy of formation of the various species:

$$
K_{D H_{i j}}\left(P_{i} \Leftrightarrow O_{i j}+\mathrm{H}_{2}\right)=e^{\left(-\frac{\Delta G_{f}^{\circ}\left(O_{i j}\right)+\Delta G_{f}^{\circ}\left(\mathrm{H}_{2}\right)-\Delta G_{f}^{\circ}\left(P_{i}\right)}{R T}\right)}
$$

In the original method, the sums in equation (1) are calculated by browsing through all the available reactions obtained through explicit generation of the detailed reaction network and adding up the appropriate terms. Hence, Vynckier and Froment (1991) proposed to reorganize the rate equation above in order to separate the rate coefficients from the factors that only depend on the reaction network and the choice of the lumps in order to arrive at a coarser a posteriori relumped reaction network. For the case of gas-phase isomerization of lump $g$ into lump $h$, they finally arrived at the following rate expression:

$$
r_{\text {isom }}(g ; h)=\frac{k_{\text {isom }}^{L}(g, h) \cdot C_{s a t} \cdot b_{g} \cdot P_{g}}{P_{\mathrm{H}_{2}} \cdot\left(1+\sum_{q} b_{F_{q}} P_{F_{q}}\right)+\sum_{q} K_{c, F_{q}} C_{s a t} b_{F_{q}} P_{F_{q}}}
$$

As earlier work (Svoboda et al., 1995; Martens and Froment, 1999; Martens and Marin, 2001) showed that the total concentration of carbenium ions could be neglected compared to the total concentration of acid sites, the forward reaction rate for the gas-phase reaction is therefore reduced to:

$$
r_{\text {isom }}(g ; h)=\frac{k_{\text {isom }}^{L}(g, h) \cdot C_{s a t} \cdot b_{g} \cdot P_{g}}{P_{\mathrm{H}_{2}} \cdot\left(1+\sum_{q} b_{F_{q}} P_{F_{q}}\right)}
$$


In this equation, the rate coefficient for the forward reaction can be decomposed into (Vynckier and Froment, 1991):

$$
\begin{aligned}
k_{\text {isom }}^{L}(g, h)= & L C_{\text {isom }(s, s)}(g, h) \cdot \tilde{K}_{\mathrm{Pr}}\left(s, O_{\text {ref }}\right) \cdot \tilde{k}_{i s o m}(s, s) \cdot C_{t}+ \\
& L C_{\text {isom }(s, t)}(g, h) \cdot \tilde{K}_{\mathrm{Pr}}\left(s, O_{\text {ref }}\right) \cdot \tilde{k}_{i s o m}(s, t) \cdot C_{t}+ \\
& L C_{\text {isom }(t, s)}(g, h) \cdot \tilde{K}_{\mathrm{Pr}}\left(t, O_{\text {ref }}\right) \cdot \tilde{k}_{i s o m}(t, s) \cdot C_{t}+(8) \\
& L C_{\text {isom }(t, t)}(g, h) \cdot \tilde{K}_{\mathrm{Pr}}\left(t, O_{\text {ref }}\right) \cdot \tilde{k}_{\text {isom }}(t, t) \cdot C_{t}
\end{aligned}
$$

where $L C_{\text {isom }(m, n)}(g, h)$ is the lumping coefficient for isomerization of lump $g$ into lump $h$ by means of an $(m, n)$ type isomerization.

In the original method (Vynckier and Froment, 1991), the lumping coefficients are calculated as a sum over all isomerization reactions of type $(m, n)$ that transform a carbenium ion of type $m$ obtained from a hydrocarbon of lump $g$ into a carbenium ion of type $n$ that corresponds to a hydrocarbon of lump $h$ : See Equation (9).

As explained elsewhere (Vynckier and Froment, 1991; Martens and Marin, 2001; Cochegrue et al., 2011), the calculation of the lumping coefficient only requires the knowledge of the detailed reaction network of elementary steps and of the choice of the lumps, but does not require the knowledge of the single event rate coefficients, as these have been explicitly isolated in the expressions above. Hence, the lumping coefficients need to be calculated only once. The lumping coefficients do, however, still depend on temperature. Indeed, $y_{i}$ represents the equilibrium mole fraction of a hydrocarbon in a given lump, which evidently depends on temperature. The same holds for the olefin isomerization and the dehydrogenation equilibrium constants. The resulting lumping coefficients exhibit a van't Hoff type temperature dependency, which is mainly due to the hydrogenation/dehydrogenation equilibrium constant, since both the values for the olefin isomerization equilibrium constant and the equilibrium mole fractions vary only slightly with temperature. In conclusion, the advantage of isolating the rate coefficients is that, for each temperature, the lumping coefficients need to be calculated only once for a given reaction network.

When dealing with heavy molecules, however, the number of species and the number of reactions grow very rapidly with carbon number, leading to immense reaction networks and resulting in excessive computation times and colossal memory requirements. Once the entire reaction network of elementary steps is finally generated, inspection of this vast network allows calculating the lumping coefficients that effectively summarize this profusion of detail into an a posteriori relumped reaction network.
Besides the original method (Vynckier and Froment, 1991), which proceeds through inspection of the detailed reaction network, two alternative ways of computing these lumping coefficients without explicitly generating the entire reaction network have been developed in the literature and are presented below.

\section{STRUCTURAL CLASS METHOD}

To avoid the explicit generation of the complete reaction network of elementary steps, Martens and Marin (2001) proposed a method based on structural classes. The main idea is based on the fact that hydrocarbon molecules can be described by combining a limited number of structures. Hence, in this approach, these structures that have the same intrinsic Gibbs energy of formation and symmetry number are listed: such a structure is a class. The sums in Equation (9) therefore reduce to sums over the classes weighted by the number of reactions that involve each species of a class. The structural class method is an enumeration technique that counts the number of species in each class. It therefore requires listing the classes and the members of the class. However, this is much faster than the exhaustive generation of all the species.

Following the structural class approach (Martens and Marin, 2001), the lumping coefficient defined by Vynckier and Froment (1991) is reorganized as follows:

$$
L C_{i s o m(m, n)}(g, h)=\frac{N_{i s o m(m, n)} \cdot K_{r e f, g}^{*}(n, T)}{K_{g}^{*}(n, T)}
$$

The factor $N_{\text {isom }(m, n)}$ represents the number of $(m, n)$ type pathways that allow to transform lump $g$ into lump $h$. It is therefore a weighted sum of the single event numbers of each $(m, n)$ reaction linking both lumps, corrected for the global symmetry number of hydrogen:

$$
N_{i s o m(m, n)}=\sum_{i \in g} \sum_{k \in g} \sum_{q \in h} \sum_{r \in h} \frac{n_{e, i k q r}}{\sigma_{R_{i k}^{+}} \cdot \sigma_{\mathrm{H}_{2}}}
$$

The factor $K_{\text {ref,g }}^{*}(n, T)$ is related to the intrinsic equilibrium coefficient of formation of the reference olefin and of hydrogen from the pure elements:

$$
K_{r e f, g}^{*}(n, T)=e^{-\frac{\Delta \tilde{G}_{f}^{o}\left(O_{r e f}\right)+\Delta \tilde{G}_{f}^{o}\left(\mathrm{H}_{2}\right)}{R T}}
$$

The factor $K_{g}^{*}(n, T)$ corresponds to the equilibrium coefficient of formation of the paraffinic lump and is calculated as the

$$
L C_{i s o m(m, n)}(g, h)=\sum_{i \in g} \sum_{k \in g} \sum_{q \in h} \sum_{r \in h} n_{e, i k q r} \cdot \frac{\sigma_{O_{i j}}}{\sigma_{R_{i k}^{+}}} \cdot \tilde{K}_{i s o m}\left(O_{i j} \Leftrightarrow O_{r e f}\right) \cdot K_{D H_{i j}}\left(P_{i} \Leftrightarrow O_{i j}+\mathrm{H}_{2}\right) \cdot y_{i}
$$


sum of the equilibrium coefficients of formation of all paraffins $P_{i}$ of lump $g$ :

$$
K_{g}^{*}(n, T)=\sum_{i \in g} e^{\left(-\frac{\Delta G_{f}^{\circ}\left(P_{i}\right)}{R T}\right)}=\sum_{i \in g} \frac{e^{-\frac{\Delta \tilde{G}_{f}^{\circ}\left(P_{i}\right)}{R T}}}{\sigma_{P_{i}}}
$$

\subsection{Computation of $K_{g}^{*}(n, T)$}

In order to calculate $K_{g}^{*}(n, T)$, one needs to compute the Gibbs enthalpy of formation of each paraffin in lump $g$. As no reliable data are available in the literature for high molecular weight species, the Gibbs enthalpy of formation is obtained by means of the Benson group contribution method (Benson et al., 1969; Benson, 1976). In this group contribution method, the values of the contributions to the enthalpy of formation, the entropy of formation and the specific heat capacity of paraffins only depend on the type (i.e., primary, secondary, tertiary or quaternary) of each carbon atom in the molecule, on the global symmetry number and on the number of gauche interactions between the carbon-carbon bonds of the molecule. Molecules with the same number of occurrences of each property in Benson's group contribution method will therefore have the same Gibbs enthalpy of formation. More precisely, paraffins can be sorted by their decomposition into Benson groups, their global symmetry number and their number of gauche interactions. Each combination of these properties is called a structural class. As a consequence, all paraffins within a lump can easily be subdivided into several structural classes with exactly the same number of occurrences of each Benson property. For paraffins, each structural class is therefore characterized by the numbers of primary $n_{p, C}$, secondary $n_{s, C}$, tertiary $n_{t, C}$, and quaternary $n_{q, C}$ carbon atoms, the minimum number of gauche interactions $n_{g c h, C}$, the number of alkanes $n_{a l k, C}$, and the global symmetry number $\sigma_{P_{i}, C}$ for paraffins in the structural class $C$. The factor $K_{g}^{*}(n, T)$ can hence be written as: See Equation (14).

with $\Delta \widetilde{G}_{f, Z}^{0}$ is the Benson group contribution to the intrinsic Gibbs free enthalpy of formation (rotation symmetries and chirality excluded) at temperature $T$ for group $Z(Z=$ primary carbon atom, secondary carbon atom, tertiary carbon atom, quaternary carbon atom, and minimum number of gauche interactions).
TABLE 1

Structural classes for monobranched alkanes $\left(\mathrm{moP}_{\mathrm{n}}\right)$ carrying one methyl or one ethyl group

\begin{tabular}{|c|c|c|c|c|c|c|c|}
\hline Alkane Class C & $n_{p, C}$ & $n_{s, C}$ & $n_{t, C}$ & $n_{q, C}$ & $\sigma_{P_{i}, C}$ & $n_{g c h, C}$ & $n_{a l k, C}$ \\
\hline & 3 & $n-4$ & 1 & 0 & 27 & 1 & 1 \\
\hline & 3 & $n-4$ & 1 & 0 & 27 & 2 & $\begin{array}{c}n \text { even: } 1 \\
n \text { odd: } 0\end{array}$ \\
\hline & 3 & $n-4$ & 1 & 0 & $27 / 2$ & 2 & $\begin{array}{c}n \text { even: }(n-6) / 2 \\
n \text { odd: }(n-5) / 2\end{array}$ \\
\hline & 3 & $n-4$ & 1 & 0 & 27 & 3 & 1 \\
\hline & 3 & $n-4$ & 1 & 0 & 27 & 3 & $\begin{array}{c}n \text { even: } 0 \\
n \text { odd: } 1\end{array}$ \\
\hline & 3 & $n-4$ & 1 & 0 & $27 / 2$ & 3 & $\begin{array}{c}n \text { even: }(n-8) / 2 \\
n \text { odd: }(n-9) / 2\end{array}$ \\
\hline
\end{tabular}

Once all the classes corresponding to one lump are known, $K_{g}^{*}(n, T)$ can be computed as a function of the number of carbon atoms $n$. By means of example, the structural classes for single branched alkanes with a methyl or an ethyl group are illustrated in Table 1 (Martens and Marin, 2001). In total, there are 6 structural classes per carbon number in which these single branched paraffins can be classified. All di- and tribranched alkanes with methyl and ethyl groups can also be sorted in a limited number of classes (Martens, 2000).

This method can easily be extended to cycloalkanes (Martens, 2000) by introducing the additional Benson groups for ring structures and providing for the additional structural classes. The structural class method was then applied to alkanes with up to three branches (methyl and/or ethyl), to monocyclic alkyl cyclopentanes with up to four substituents and only one substituent longer than methyl, and to non-pericondensed alkyl cyclohexanes with up to four six-membered rings and up to four substituents with only one substituent longer than methyl (Martens, 2000; Martens and Marin, 2001).

$$
K_{g}^{*}(n, T)=\sum_{C}^{n_{\text {classes }}} \frac{n_{a l k, C}}{\sigma_{P_{i}, C}} e^{-\frac{n_{p, C} \Delta \tilde{G}_{f, p}^{o}}{R T}} \cdot e^{-\frac{n_{s, C} \Delta \tilde{G}_{f, s}^{o}}{R T}} \cdot e^{-\frac{n_{t, c} \Delta \tilde{G}_{f, t}^{o}}{R T}} \cdot e^{-\frac{n_{q, C} \Delta \tilde{G}_{f, q}^{o}}{R T}} \cdot e^{-\frac{n_{g c h, C} \Delta \tilde{G}_{f, g c h}^{o}}{R T}}
$$




\subsection{Computation of $N_{\text {isom }(m, n)}$}

In order to calculate $N_{\text {isom }}(m, n)$ for a given reaction, one needs to compute the global symmetry number of all carbenium ions that are able to react according to this pathway, together with its corresponding number of single events for this reaction, i.e. the ratio of the global symmetry number of the reacting carbenium ion to the global symmetry number of the corresponding transition state. According to the same procedure, Martens and Marin (2001) used the concept of structural classes for the various types of carbenium ions. For example, considering the secondary to tertiary PCP isomerizations between dibranched paraffins and monobranched paraffins, they found 5 structural classes of secondary dibranched carbenium ions that are able to react according to a PCP step with formation of a tertiary monobranched carbenium ion. Table 2 lists these 5 classes of carbenium ions, together with their global symmetry number $\sigma_{R_{i k}^{+}}$, their number of single events $n_{e, i k q r}$ for the secondary to tertiary PCP isomerization and the number of carbenium ions $n_{\text {ions }, C}$ in each structural class $C$. Hence, the factor $N_{i s o m(m, n)}$ for secondary - tertiary PCP isomerization from dibranched paraffins to monobranched paraffins can be computed by added up the various contributions of each structural class:

$$
N_{P C P(s, t)}\left(\operatorname{diP}_{n} ; m o P_{n}\right)=\frac{12 n-78}{81}=\frac{12(n-7)+6}{81}
$$

for $n \geq 10$

TABLE 2

Structural classes of carbenium ions contributing to $N_{\mathrm{PCP}(\mathrm{s}, \mathrm{t})}\left(\mathrm{diP}_{\mathrm{n}} ; \mathrm{moP}_{\mathrm{n}}\right)$

\begin{tabular}{c|c|c|c|c}
\hline Carbenium ion class $C$ & $\sigma_{R_{i k}^{+}}$ & $n_{e, i k q r}$ & $n_{\text {ions }, C}$ & $\frac{n_{e, i k q r} \cdot n_{\text {ions }, C}}{\sigma_{R_{i k}^{+}} \cdot \sigma_{\mathrm{H}_{2}}}$ \\
\hline$P_{+} \mathrm{Cx}$ & 243 & 18 & 1 & $3 / 81$ \\
\hline & 81 & 12 & $n-6$ & $6(n-6) / 81$ \\
\hline
\end{tabular}

This expression is valid only for $n \geq 10$, as not all structural classes contribute to this reaction for lower carbon numbers.

Again, this approach can easily be extended to isomerization of the other paraffin lumps and to the various isomerization reactions of cycloalkanes (Martens, 2000) by introducing the corresponding structural classes of carbenium ions. Moreover, the approach has also been extended to cracking reactions, as illustrated by Martens and Marin (2001) for the cracking of the lump of branched monocycloalkanes into a lump of lighter monocycloalkanes and a lump of dibranched alkanes.

As mentioned above, the method of structural classes avoids the excessive calculation times required for the explicit generation of the entire reaction network of elementary reaction steps by directly calculating the lumping coefficient of the various types of reactions. For small degrees of branching in the molecules, this approach is extremely interesting because it allows obtaining an analytical formulation of the lumping coefficient without the need to enumerate too many different structural classes.

\section{LATERAL CHAIN METHOD}

To avoid the explicit generation of the complete reaction network of elementary steps, Valéry (2002) proposed a method based on lateral chain decomposition. The main idea is based on the fact that hydrocarbon molecules and their intermediates can be decomposed into lateral chains and active centres. Focusing on the intermediate activated complex, Valéry (2002) used an alternate method to predict the properties of these complexes and especially the sum of reciprocal of the symmetry numbers. This recursive method was also applied for the evaluation of the sum of energy terms. In the lateral chain decomposition method, the calculation of the lumping coefficients is based on an efficient computer algorithm that only needs to know the maximum number of carbon atoms and the maximum degree of branching of the species in the reaction network.

Rearranging Equation (1) in a similar way as above yields:

$$
\begin{aligned}
& r_{\{\operatorname{reac}(m, u)}=L C_{\text {reac }(m, u)}\left(F_{o} \rightarrow F_{p}\left(+F_{q}\right)\right) \text {. } \\
& \tilde{K}_{\mathrm{Pr}}\left(m, O_{r e f}\right) \cdot \tilde{k}_{\text {reac }}(m, u) \cdot \frac{C_{t} \cdot C_{s a t} \cdot b_{F_{g}} \cdot P_{F_{o}}}{P_{\mathrm{H}_{2}} \cdot D E N^{g}+D E N_{\text {acid }}^{g}}
\end{aligned}
$$

with the lumping coefficient $L C_{\text {reac }(m, u)}\left(F_{o} \rightarrow F_{p}\left(+F_{q}\right)\right)$ defined as in Equation (9).

In the lateral chain decomposition method (Valéry, 2000, 2002; Valéry et al., 2007; Mitsios et al., 2009), the lumping 
coefficient defined by Vynckier and Froment (1991) is reorganized as follows:

$$
\begin{aligned}
& L C_{\text {reac }(m, u)}\left(F_{o} \rightarrow F_{p}\left(+F_{q}\right)\right)=e^{-\frac{\Delta \tilde{G}_{f}^{o}\left(O_{r e f}\right)+\Delta G_{f}^{o}\left(\mathrm{H}_{2}\right)}{R T}} \\
& \cdot \frac{1}{\sum_{P_{i} \in F_{o}} e^{\left(-\frac{\Delta G_{f}^{\circ}\left(P_{i}\right)}{R T}\right)}} \cdot\left(\sum_{i k l \in\left\{\underset{r \operatorname{reac}(m, u)}{\left.F_{o} \rightarrow F_{p}\left(+F_{q}\right)\right\}}\right.} \frac{1}{\sigma_{\#_{i k l}}}\right)
\end{aligned}
$$

In this expression, three factors can be distinguished. The first factor is related to the equilibrium coefficient of formation of the reference olefin and of hydrogen from the pure elements. This factor only depends on the number of carbon atoms of the reacting lump. The second factor in Equation (17) represents the inverse of the equilibrium constant of formation of the paraffinic lump and is calculated as the sum of the equilibrium constants of formation of all paraffins $P_{i}$ of lump $F_{o}$. The third factor in Equation (17) represents the number of $(m, n)$ type pathways that allow to transform lump $F_{o}$ according to this lumped reaction.

With respect to the structural class approach, the first factor corresponds to $\left(\sigma_{\mathrm{H}_{2}}\right)^{-1} \cdot K_{r e f, g}^{*}(n, T)$, the second factor corresponds to the reciprocal of $K_{g}^{*}(n, T)$, while the third factor corresponds to the reciprocal of $\sigma_{\mathrm{H}_{2}} \cdot N_{\text {isom }(m, n)}$. This clearly illustrates that both the structural class approach and the lateral chain decomposition method, although developed independently, regroup in a very similar manner the various factors included in the lumped coefficients of Equation (9) that were originally defined by Vynckier and Froment (1991). The main difference between both methods therefore resides in the way of calculating the various factors.
For the lumping coefficients calculated by the lateral chain decomposition method (Eq. 17), the first two factors are energy terms that are obtained from Benson's group contribution method (Benson et al., 1969; Benson, 1976) in order to maintain the necessary consistency for high molecular weight species. The last factor to be calculated for the lumping coefficient is the sum over the symmetry numbers of all activated complexes occurring in these transformations. It is important to note that, in this lateral chain decomposition approach, this last factor is independent of the produced ions $R_{q r}^{+}$, but only depends on the reacting ion $R_{i k}^{+}$and on the various activated complexes that result from it. This means that calculating a lumping coefficient requires only knowledge of the ions involved, and thus of the resulting activated complexes, instead of a list of the elementary steps. However, the sum extends over all the steps, and some may involve the same activated complex $\#_{i k l}$. To calculate the last factor, we will therefore first take a closer look at the representation of the activated complexes, before describing the recursive formulae for the computation of the factors in the lumping coefficients. For the case of comparison with the structural class method, it is assumed in what follows that the branches in the lateral chains are only methyl or ethyl substituents.

\subsection{Description of an Activated Complex}

An activated complex \# can be decomposed into three parts:

- an "activated zone", ZA, that carries the positive charge and is characteristic of the elementary step considered;

- a first lateral chain, $A$;

- a second lateral chain, $B$.

In Figure 2, this is illustrated for $\beta$-scission and PCP isomerization reactions. As both lateral chains lie outside the
Activated complex for $\beta$-scission steps

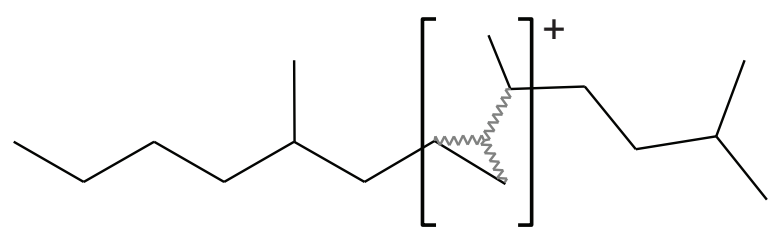

A

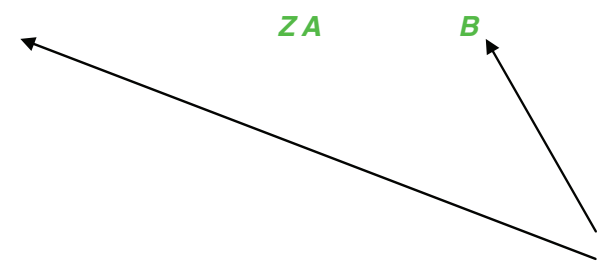

Figure 2
Activated complex for PCP steps
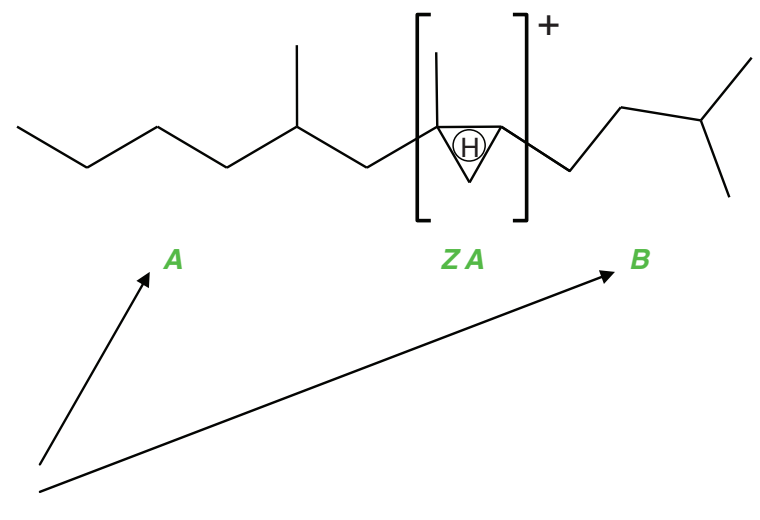

Illustration of the two types of activated complexes. 
activated zone that is characteristic of the elementary step, the actual lateral chains do not depend on the reaction type, nor do they influence the reaction.

\subsection{Recursive Algorithm for Calculating the Overall Number of $(m, n)$ Type Pathways}

The overall number of $(m, n)$ type pathways that allow to transform lump $F_{o}$ according to the lumped reaction is given by the sum of reciprocal of the global symmetry numbers of the activated complexes $\sigma_{\#}$, as shown is Equation (17). As described above, in the lateral chain decomposition method, the activated complex is represented by an activated zone and two lateral chains. The global symmetry number $\sigma_{\#}$ of the activated complex \# is therefore given by:

$$
\sigma_{\#}=\sigma_{A} \cdot \sigma_{Z A} \cdot \sigma_{B} \cdot \sigma_{e x t(A-Z A-B)}
$$

where $\sigma_{Z A} \quad$ is the partial symmetry number for the activated zone,

$\sigma_{A}, \sigma_{B} \quad$ are the partial symmetry numbers for the lateral chains,

$\sigma_{\text {ext }(A-Z A-B)}$ is the external symmetry number of the activated complex.

Hence, the sum of reciprocal of the global symmetry numbers of the activated complexes $\sigma_{\#}$ now becomes:

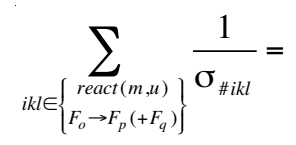

$$
\begin{aligned}
& \sum_{A-Z A-B \in\{R\}} \frac{n_{o c c(A-Z A-B)}}{\sigma_{A} \cdot \sigma_{Z A} \cdot \sigma_{B} \cdot \sigma_{e x t(A-Z A-B)}}
\end{aligned}
$$

where $\{R\}$

is the set of the activated complexes, $A-Z A-B$, involved in reactions of type $(m, u)$ going from lump $F_{o}$ to lump $F_{p}$ (and $F_{q}$ in the case of a $\beta$-scission), $n_{\text {occ }(A-Z A-B)}$ is the number of reactions of type $(m, u)$ that involve activated complex $A-Z A-B$.

For $\beta$-scission, a given activated complex is only involved in a single cracking step because the complex is an "intermediate hybrid" between the reacting carbenium ion, and the resulting ion and olefin (Fig. 3). As a consequence $n_{o c c}=1$ for any $\beta$-scission step. For PCP-isomerizations, the same activated complex is linked to four different carbenium sions, as shown in Figure 4. Given the assumptions used in the $a$ posteriori relumping scheme, the carbenium ions (I) and (II) belong to the same lump, as do the two carbenium ions (III) and (IV). In total, there are six possible pathways linking these four carbenium ions. However, the isomerization between ions (I) and (II) does not appear in the relumped network, as both ions pertain to the same lump. The same holds for the isomerization between ions (III) and (IV). Hence, 4 different PCP isomerizations with a change of degree of branching between these different lumps and involving the same activated complex still remain, and $n_{o c c}=4$. However, in case $A=B$ and $L_{1}=L_{2}$, these four different possibilities degenerate into a single isomerization step $\left(n_{\text {occ }}=1\right)$. If in addition $L_{3}=L_{4}$, this isomerization step involves an activated complex that has an external symmetry of 2 .

For a given relumped reaction, several pathways may be followed to proceed from the reacting lump to the product lump(s). For each path, the activated complex needs to be identified in order to be able to define the set of the activated complexes $\{R\}$ involved in the reaction. Figure 5 illustrates the set of the 30 activated complexes $A-Z A-B$ involved in the $(s, s) \beta$-scission of a tri-branched hexadecane into a monobranched secondary hexyl carbenium ion and a monobranched decene. From this Figure, it can be observed that for this reaction, two different activated zones $Z A$ are present in the set, one activated zone with 4 carbon atoms containing a methyl substituent and an activated zone with 5 carbon atoms containing an ethyl substituent. For a given activated zone, the various structural isomers of the two lateral chains appear.

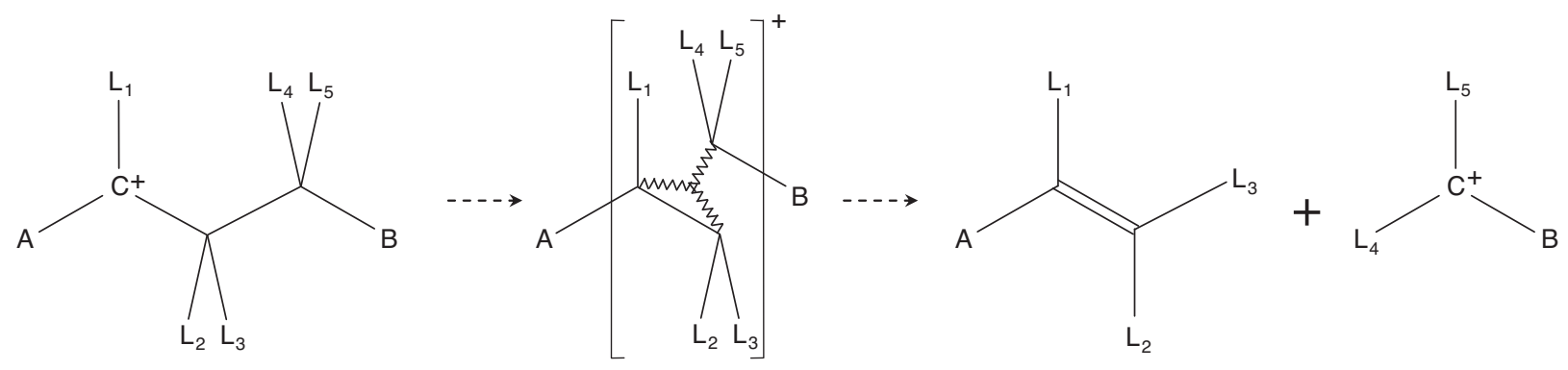

Figure 3

Reaction pathway and activated complex for a $\beta$-scission step of a carbenium ion into a smaller carbenium ion and an olefin. $L_{1}$ to $L_{5}$ are substituents that are part of the activated zone, while $A$ and $B$ are lateral chains, which do not participate in the cracking reaction. 
(I)

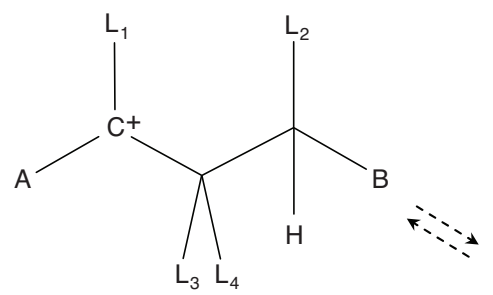

(II)

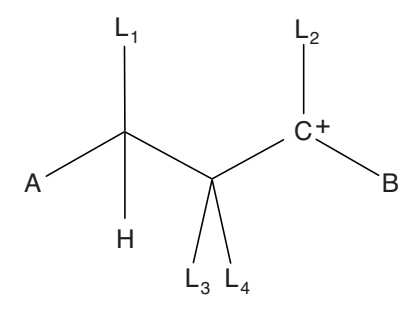

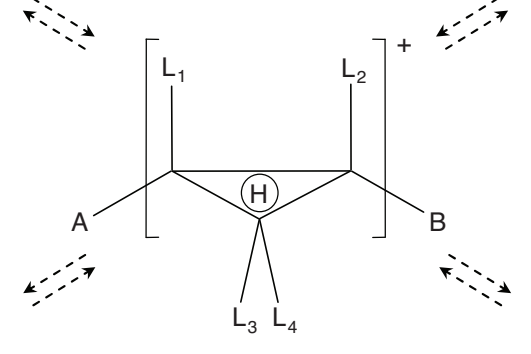

A<smiles>CCC(C)C1(C)CC1</smiles>

(III)

(IV)

Figure 4

Reaction pathway and activated complex for a PCP-isomerization step of a carbenium ion. For a given activated complex, several PCPisomerization steps are possible unless the external symmetry of the reacting ion causes the steps to be identical. $L_{1}$ to $L_{4}$ are substituents that are part of the activated zone, while $A$ and $B$ are lateral chains, which do not participate in the PCP rearrangement.
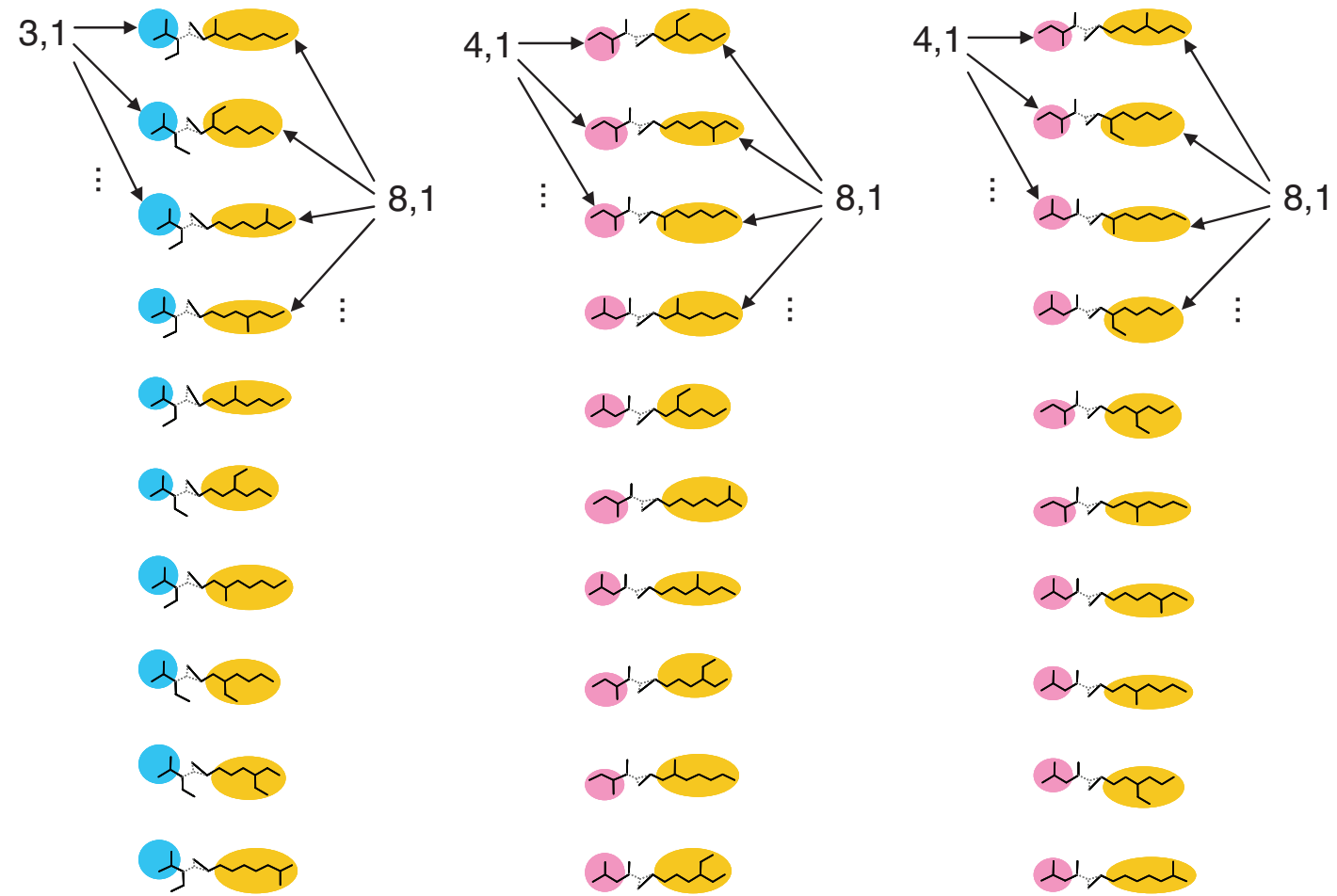

Figure 5

Set of the 30 activated complexes involved in the $(s, s) \beta$-scission of a tri-branched hexadecane into a monobranched secondary hexyl carbenium ion and a monobranched decene 
In order to evaluate Equation (19), it is therefore further decomposed into:

- a sum over the various activated zones $Z A$,

- a sub-sum over lateral chains A that have a given number of carbon atoms, $n_{c, A}$, and a given number of lateral branches, $n_{b, A}$.

In a given lump, choosing an activated zone with $n_{c Z A}$ carbon atoms and with $n_{b, Z A}$ branches determines the number of carbon atoms and the number of lateral branches that are still available for the lateral chains $A$ and $B$. A set of lateral chains $A$ with a given carbon number $n_{c A}$ and branching degree $n_{b, A}$ will be termed "equivalent lateral chains". Once the class of equivalent lateral chains $A$ and the activated zone are selected, the class of equivalent lateral chains $B$ (i.e., $n_{c, B}$ and $n_{b, B}$ ) is fixed because the total number of carbon atoms and the total number of branches are determined by the lump. Activated complexes are said to be "homologous activated complexes" when they have the same activated zone and when the lateral chains $A$ (or $B$, equivalently) belong to the same equivalence class.

Figure 6 illustrates the concepts of equivalent lateral chains and of homologous activated complexes. As shown in Figure 5, there are 2 structures for the activated zone involved in the $(s, s) \beta$-scission of a tri-branched $\mathrm{C}_{16}$ paraffin into a monobranched secondary hexyl carbenium ion and a monobranched decene, one activated zone with 4 carbon atoms containing a methyl branch and one with 5 carbon atoms containing an ethyl branch. For the activated zone with 4 carbon atoms, there are 2 possible monobranched lateral chains with 4 carbon atoms and 10 possible monobranched lateral chains with 8 carbon atoms (Fig. 6). There are therefore $2 \times 10=20$ homologous activated complexes with an activated zone of 4 carbon atoms and containing a methyl branch. For the activated zone with 5 carbon atoms containing an ethyl branch, there is a single monobranched lateral chain with 3 carbon atoms and there are again 10 possible monobranched lateral chains with 8 carbon atoms, resulting in 10 homologous activated complexes. Hence, the total set of the activated complexes involved in the $(s, s) \beta$-scission of a tri-branched hexadecane into a monobranched secondary hexyl carbenium ion and a monobranched decene amounts to 30, as was already shown in Figure 5.

In what follows, we will exemplify the lateral chain decomposition approach for $\beta$-scission reactions. For details concerning PCP-isomerization steps, the reader is referred to Valéry (2002). For $\beta$-scission reactions, the following simplifications apply:

- there is only one $\beta$-scission reaction for a given activated complex, i.e. $n_{o c c}=1$;

- as the activated zone contains a 2-electron 3-center bond without flexibility for free rotation around this bond, there is no external symmetry due to its rigid structure, i.e. $\sigma_{\mathrm{ext}}=1$;
- the activated complex of a $\beta$-scission reaction has the same number of carbon atoms and the same degree of branching as the reacting paraffin;

- the equivalence class of lateral chains are defined by the lumps of the product ion and olefin.

After introducing these simplifications and decomposing into sub-sums, Equation (19) can be rewritten as follows:

$$
\begin{aligned}
& \sum_{A-Z A-B \in R} \frac{1}{\sigma_{A} \cdot \sigma_{Z A} \cdot \sigma_{B}}=\sum_{Z A} \frac{1}{\sigma_{Z A}} \cdot \underbrace{[.}_{\left.\begin{array}{l}
\sum_{A \in\left\{n_{c, A} \text { carbons }\right\}} \frac{1}{\left.\sigma_{b, A} \text { branches }\right\}} \\
\text { sum over lateral chains }
\end{array}\right]}
\end{aligned}
$$

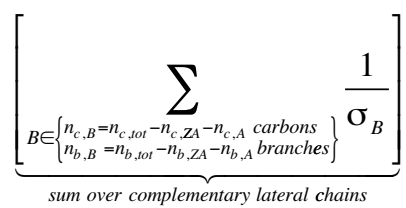

In Equation (20), the various homologous activated complexes are the individual contributions to each term of the sum over $Z A$. The sum over the lateral chains and the sum over the complementary lateral chains in Equation (20) can be calculated by a recursive method. Let $n_{p}$ be the number of carbon atoms of the "main chain" of a lateral chain. The main chain is easily identified, as it is the longest linear chain of the lateral chain. The lateral chain is therefore composed of a terminal $\mathrm{CH}_{3}$ group and successive elementary patterns chosen among - $\mathrm{CH}_{2^{-}}$, -CHMe-, -CHEt-, -CMeMe-, -CMeEt-, and -CEtEt-. Each of these patterns contributes to the length of the main chain. Figure 7 shows the six possibilities for increasing the length of a lateral chain starting from $\mathrm{CH}_{3}$ - If $\sigma_{L}$ is the symmetry number of the lateral chain with $n_{p}$ carbons along the main chain, then the symmetry number after inserting an additional pattern is $\sigma_{L}$ times the symmetry number of that pattern. Let $U_{S}\left(n_{p}, n_{c}, n_{b}\right)$ be defined by:

$$
U_{S}\left(n_{p}, n_{c}, n_{b}\right)=\sum_{A \in\left\{\begin{array}{c}
\text { Length of main chain } n_{p} \\
\text { Number of carbon atoms }=n_{c} \\
\text { Number of branches }=n_{b}
\end{array}\right.} \frac{1}{\sigma_{A}}
$$

The recursion formula based on "pattern insertion" (Fig. 7) then becomes: see Equation (22).

This formula is valid for $n_{p}>3$. For low values of $n_{b}$ or $n_{c}$, the second or third argument of the function $U_{S}$ may become negative; in this case the contribution to $U_{S}$ is set to 0 . Ignoring chirality, the symmetry number (1, 3 or 9$)$ of the inserted pattern is defined by the structure of the allowed lateral branches $\left(-\mathrm{H},-\mathrm{CH}_{3},-\mathrm{C}_{2} \mathrm{H}_{5}\right.$ in this example, as explained above). Chirality is possible as soon as the chain on the left of the inserted pattern contains more than 3 carbon atoms (i.e., different from $-\mathrm{H},-\mathrm{CH}_{3}$ and $-\mathrm{C}_{2} \mathrm{H}_{5}$ ): the central carbon is chiral when its two remaining substituents are different. In this case, the global symmetry number is divided by 2 . Further details and formulae for $n_{p} \leq 3$ are given in Valéry 
Figure 6

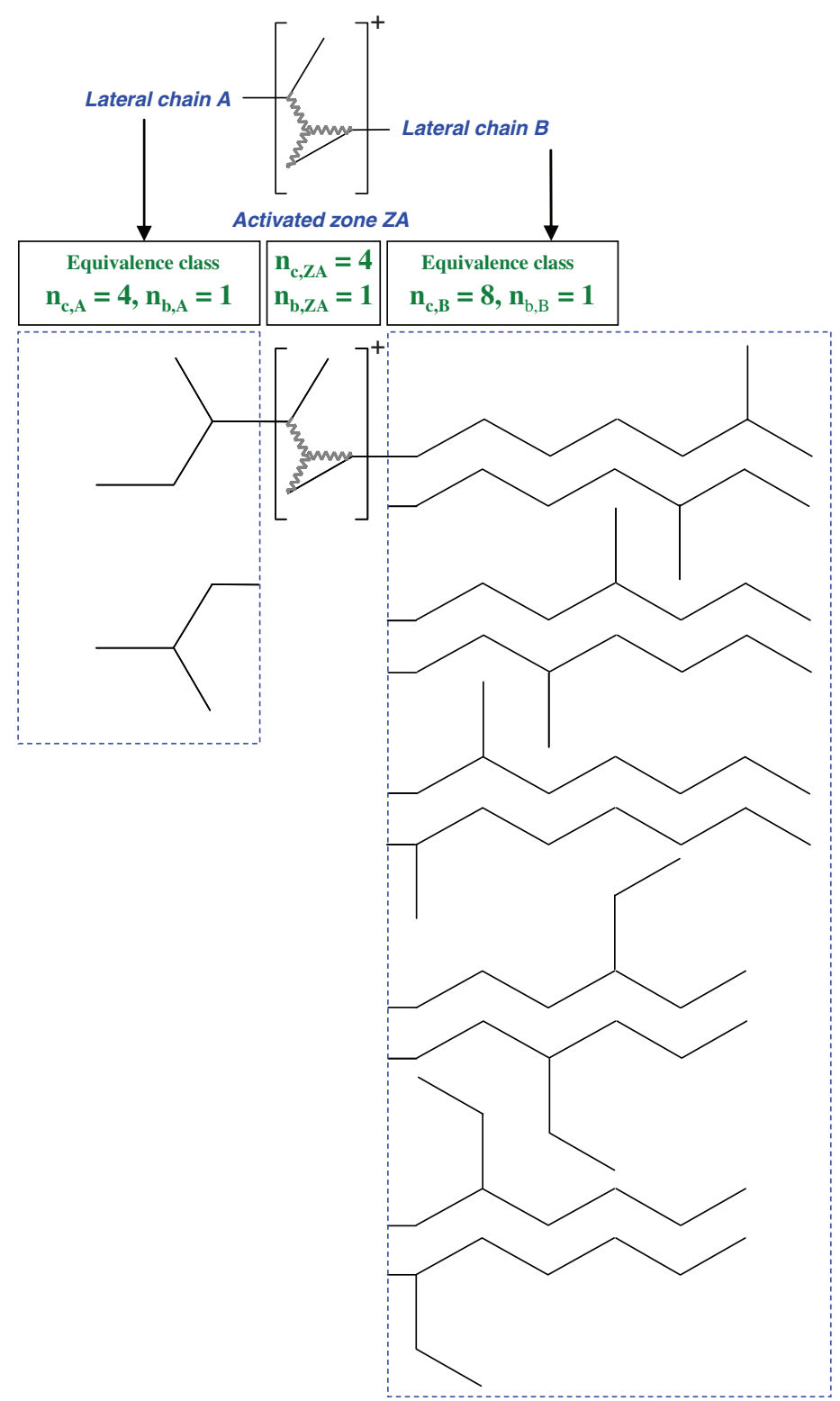

Example of homologous activated complexes and equivalent lateral chains.

$$
\begin{aligned}
U_{S}\left(n_{p}, n_{c}, n_{b}\right)= & U_{S}\left(n_{p}-1, n_{c}-1, n_{b}\right) \times 1 & -\mathrm{CH}_{2}-\text { insertion } & \left(\sigma_{\mathrm{CH}_{2}}=1\right) \\
& +U_{S}\left(n_{p}-1, n_{c}-2, n_{b}-1\right) \times \frac{2}{3} & -\mathrm{CHMe}-\text { insertion } & \left(\sigma_{\mathrm{CHMe}}=3 / 2\right) \\
& +U_{S}\left(n_{p}-1, n_{c}-3, n_{b}-1\right) \times \frac{2}{3} & -\mathrm{CHEt}-\text { insertion } & \left(\sigma_{\mathrm{CHEt}}=3 / 2\right) \\
& +U_{S}\left(n_{p}-1, n_{c}-3, n_{b}-2\right) \times \frac{1}{9} & -\mathrm{CMeMe}-\text { insertion } & \left(\sigma_{\mathrm{CMeMe}}=9\right) \\
& +U_{S}\left(n_{p}-1, n_{c}-4, n_{b}-2\right) \times \frac{2}{9} & - \text { CEtMe- insertion } & \left(\sigma_{C \mathrm{EtMe}}=9 / 2\right) \\
& +U_{S}\left(n_{p}-1, n_{c}-5, n_{b}-2\right) \times \frac{1}{9} & -\mathrm{CEtEt}-\text { insertion } & \left(\sigma_{\mathrm{CEEtEt}}=9\right)
\end{aligned}
$$




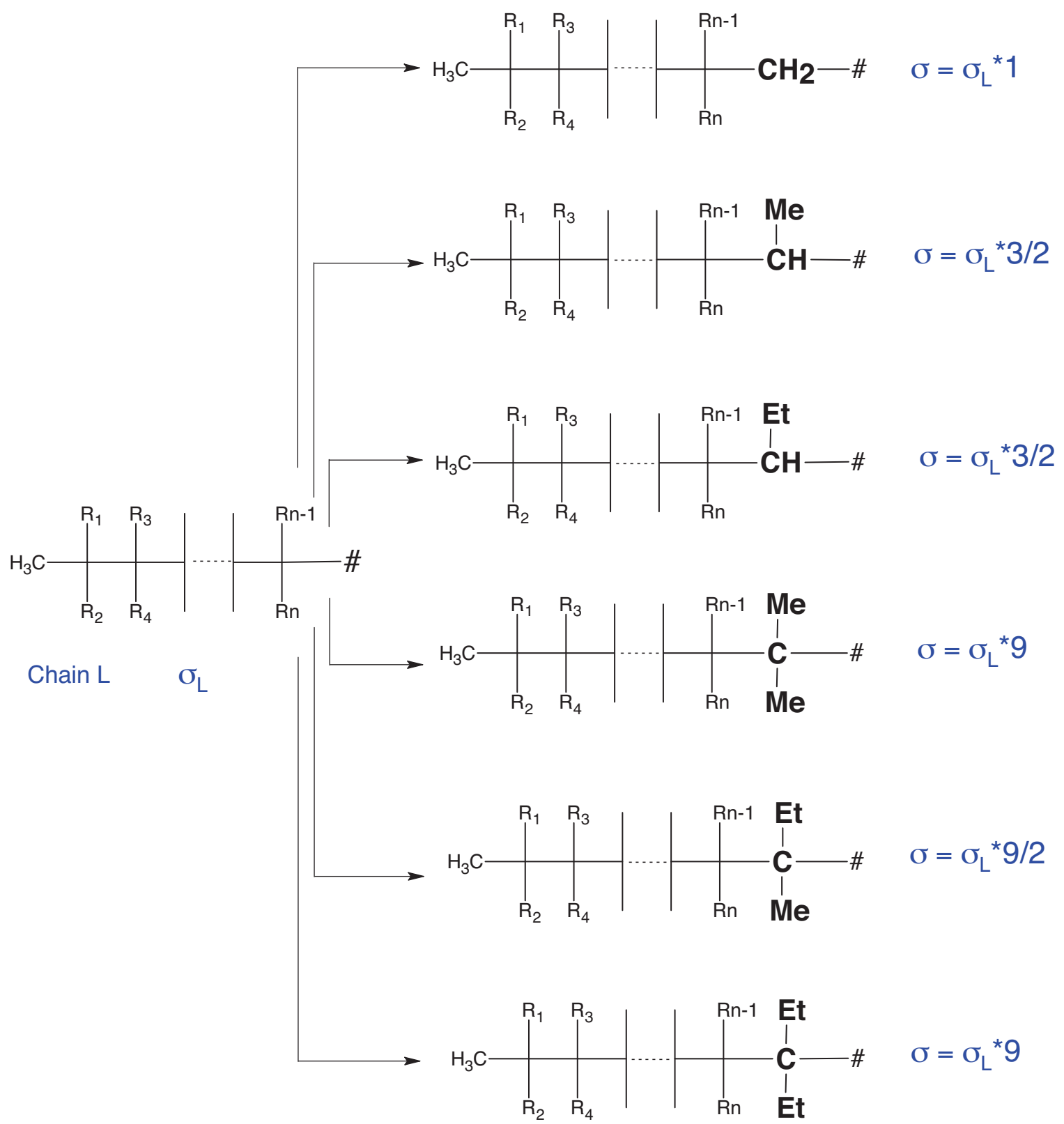

Figure 7

Concept of the recursive "pattern insertion" method for calculating the symmetry number of a lateral chain.

et al. (2007). We finally define the Symmetry Property of Lateral Chains $\operatorname{SPLC}\left(n_{c}, n_{b}\right)$ as:

$$
\begin{aligned}
& \operatorname{SPLC}\left(n_{c}, n_{b}\right)= \\
& \sum_{n_{p}=n_{c}-2 n_{b}}^{n_{p}=n_{c}} U_{S}\left(n_{p}, n_{c}, n_{b}\right)=\sum_{A \in\left\{\begin{array}{c}
n c \text { carbons } \\
\text { b branchings }\}
\end{array}\right.} \frac{1}{\sigma_{A}}
\end{aligned}
$$

This is exactly the sum within square brackets in Equation (20). The starting value of index $n_{p}$ in this sum is obtained when all the branches are ethyl groups $\left(n_{p}=n_{c}-2 n_{b}\right)$, the maximum value when the lateral chain is linear $\left(n_{p}=n_{c}\right)$.

For $\beta$-scission reactions, Equation (20) can therefore be written as:

$$
\begin{aligned}
& \sum_{A-Z A-B \in R} \frac{1}{\sigma_{A} \cdot \sigma_{Z A} \cdot \sigma_{B}}= \\
& \sum_{Z A} \frac{1}{\sigma_{Z A}} \cdot \operatorname{SPLC}\left(n_{c, A}, n_{b, A}\right) \cdot \operatorname{SPLC}\left(n_{c, B}, n_{b, B}\right)
\end{aligned}
$$

In this expression, the symmetry number of the activated zone still remains to be determined. It is derived from simple 
properties of the activated complex of Figure 3. Let $n_{L_{i}}=0$ when $L_{i}$ is a hydrogen substituent and $n_{L_{i}}=1$ otherwise. The internal symmetry number for each $L_{i}$ group is then $\sigma_{\text {int } L_{i}}=3^{n} L_{L_{i}}$. Chirality is born by three carbon atoms involved in the 2-electron 3-center bond. These carbon atoms are chiral when their substituents are different. Note that when the lateral chains $A$ and $B$ are more than 2 carbon atoms long, the chirality of the activated zone does no longer depend on these chains as in this example $L_{1}$ to $L_{5}$ are at most ethyl branches. Finally, the symmetry number of the activated zone is therefore given by:

$$
\sigma_{Z A}=\frac{3^{n_{L_{1}}+n_{L_{2}}+n_{L_{3}}+n_{L_{4}}+n_{L_{5}}}}{2^{n_{c h}}}
$$

where $n_{c h}$ is the number of chiral carbon atoms among the three carbon atoms of the 2-electron 3-center bond. Inserting Equation (25) into Equation (24) therefore allows calculating the last factor of the expression for the lumping coefficient defined by Equation (17) by means of an elegant method that does not require the exhaustive generation of the reaction network.

\subsection{Recursive Algorithm for Calculating the Equilibrium Constant of Formation of the Paraffinic Lump}

As mentioned above, the second factor in the expression for the lumping coefficients $(E q .17)$ represents the reciprocal of the equilibrium constant of formation of the paraffinic lump. This equilibrium constant calculated as the sum of the equilibrium constants of formation of all paraffins $P_{i}$ of lump $F_{o}$ :

$$
\sum_{P_{i} \in F_{0}} e^{\left(-\frac{\Delta G_{f}^{0}\left(P_{i}\right)}{R T}\right)}=\sum_{P_{i} \in F_{0}} \frac{e^{\left(-\frac{\Delta \tilde{G}_{f}^{0}\left(P_{i}\right)}{R T}\right)}}{\sigma_{P_{i}}}
$$

where $\Delta \widetilde{G}_{f}^{0}\left(P_{i}\right)$ is the intrinsic Gibbs energy of formation of paraffin $P_{i}$, whose value can be calculated using Benson's group contribution method. Here also, a recursive algorithm can be used. For the sake of simplicity, the gauche interactions and the external symmetry of the paraffins will be ignored in our example. The method does, however, account for these symmetrical molecules, and the reader is referred to Valéry (2002) for further details.

The method is once again based on the concept of lateral chains as defined above: a given paraffin can be decomposed into two zones, as has been done with activated complexes, but this time without an activated zone. In this approach, a paraffin with $n_{p}$ carbon atoms along the main chain is therefore the concatenation of a lateral chain $A$ with $n_{p, A}$ carbon atoms and a lateral chain $B$ with $n_{p, B}\left(=n_{p}-n_{p, A}\right)$ carbon atoms along their respective main chains. The symmetry number of the concatenated chains is the product of the symmetry numbers of the both chains (ignoring external symmetry), while the intrinsic Gibbs energy is the sum of the individual Gibbs energies (ignoring gauche interactions). The exponential of the normalized intrinsic Gibbs energy is then the product of the exponentials of the two lateral chains. Hence, Equation (26) is rewritten as:

$$
\begin{aligned}
& \sum_{\substack{P_{i} \in F_{0} \\
P_{i}=A-B}} \frac{e^{\left(-\frac{\Delta \tilde{G}_{f}^{0}\left(P_{i}\right)}{R T}\right)}}{\sigma_{P_{i}}}=\frac{1}{2} . \\
& \sum_{\begin{array}{c}
\text { A:chains with } \\
\text { carbons along the } \\
\text { main chain }
\end{array}}\left(\frac{e^{\left(-\frac{\Delta \tilde{G}_{f}^{0}(A)}{R T}\right)}}{\sigma_{A}} \cdot \sum_{\begin{array}{l}
\text { equivalent } B \text { chains } \\
\text { such that } A-B \in F_{0}
\end{array}} \frac{e^{\left(-\frac{\Delta \tilde{G}_{f}^{0}(B)}{R T}\right)}}{\sigma_{B}}\right)
\end{aligned}
$$

The factor $1 / 2$ results from the fact that chains $A$ and $B$ can be interchanged, i.e. a paraffin can be considered either as $A-B$ or as $B-A$. The length $n_{p, A}$ of chain $A$ is arbitrary and remains to be chosen. For reasons of chirality (Valéry et al., 2007), we set $n_{p, A}=3$. The properties of chain $B$ can then be calculated using the "pattern insertion" method discussed in the previous section. Let:

$$
U_{T}\left(n_{p}, n_{c}, n_{b}\right)=\sum_{\substack{n_{p} \text { length of main chain } \\
A \in\left\{\begin{array}{l}
n_{n} \text { carbon atoms } \\
n_{b} \text { lateral branches }
\end{array}\right.}} \frac{e^{\left(-\frac{\Delta \tilde{G}_{f}^{0}(A)}{R T}\right)}}{\sigma_{A}}
$$

We now define the Thermodynamic Property of Lateral Chains $\operatorname{TPLC}\left(n_{c}, n_{b}\right)$ as:

$$
\begin{gathered}
\operatorname{TPLC}\left(n_{c}, n_{b}\right)=\sum_{A \in\left\{\begin{array}{l}
n_{c} \text { carbon atoms } \\
\left.n_{b} \text { lateral branches }\right\}
\end{array}\right.} \frac{e^{\left(-\frac{\Delta G_{f}^{*}(A)}{R T}\right)}}{\sigma_{A}}= \\
\sum_{n_{p}=n_{c}-2 n_{b}}^{n_{p}=n_{c}} U_{T}\left(n_{p}, n_{c}, n_{b}\right)
\end{gathered}
$$

Again, the minimum value of index $n_{p}$ in this last sum is obtained when all the branches are ethyl groups $\left(n_{p}=n_{c}-\right.$ $2 n_{b}$ ), while the maximum value is given when the lateral chain is linear $\left(n_{p}=n_{c}\right)$.

When choosing $n_{p, A}$ equal to 3, Equation (27) becomes: see Equation (30).

Finally, using the "pattern insertion" concept and based in Figure 7 and Equation (22), $U_{T}$ can be obtained recursively as: see Equation (31).

Further details and the initial $U_{T}\left(3, n_{c}, n_{b}\right)$ are given in Valéry et al. (2007). 


$$
\begin{aligned}
U_{T}\left(n_{p}, n_{c}, n_{b}\right)= & U_{T}\left(n_{p}-1, n_{c}-1, n_{b}\right) \times 1 \times e^{-\frac{\Delta \tilde{\sigma}_{f}^{0}\left(\mathrm{CH}_{2}\right)}{R T}} & & -\mathrm{CH}_{2}- \\
& +U_{T}\left(n_{p}-1, n_{c}-2, n_{b}-1\right) \times \frac{2}{3} \times e^{-\frac{\Delta \tilde{G}_{f}^{0}\left(\mathrm{CH}_{3}\right)+\Delta \tilde{G}_{f}^{0}(\mathrm{CH})}{R T}} & & -\mathrm{CHMe}- \\
& +U_{T}\left(n_{p}-1, n_{c}-3, n_{b}-1\right) \times \frac{2}{3} \times e^{-\frac{\Delta \tilde{G}_{f}^{0}\left(\mathrm{CH}_{3}\right)+\Delta \tilde{G}_{f}^{0}\left(\mathrm{CH}_{2}\right)+\Delta \tilde{G}_{f}^{0}(\mathrm{CH})}{R T}} & & -\mathrm{CHEt}- \\
& +U_{T}\left(n_{p}-1, n_{c}-3, n_{b}-2\right) \times \frac{1}{9} \times e^{-\frac{2 \Delta \tilde{G}_{f}^{0}\left(\mathrm{CH}_{3}\right)+\Delta \tilde{G}_{f}^{0}(\mathrm{C})}{R T}} & & -\mathrm{CMeMe}- \\
& +U_{T}\left(n_{p}-1, n_{c}-4, n_{b}-2\right) \times \frac{2}{9} \times e^{-\frac{2 \Delta \tilde{G}_{f}^{0}\left(\mathrm{CH}_{3}\right)+\Delta \tilde{G}_{f}^{0}\left(\mathrm{CH}_{2}\right)+\Delta \tilde{G}_{f}^{0}(\mathrm{C})}{R T}} & & -\mathrm{CEtMe}- \\
& +U_{T}\left(n_{p}-1, n_{c}-5, n_{b}-2\right) \times \frac{1}{9} \times e^{-\frac{2 \Delta \tilde{G}_{f}^{0}\left(\mathrm{CH}_{3}\right)+2 \Delta \tilde{G}_{f}^{0}\left(\mathrm{CH}_{2}\right)+\Delta \tilde{G}_{f}^{0}(\mathrm{C})}{R T}} & & -\mathrm{CEtEt}-
\end{aligned}
$$

As a conclusion, Equations (22-25) and (29-31) allow to calculate the lumping coefficients much faster than the original method, which needs to generate the complete reaction network and to determine the lumping coefficients by inspecting the complete list of single events in a generated reaction network. The lateral chain decomposition method is a quite flexible method, as it can easily be extended to include different type of lateral branches, such as $n$-propyl, $i$-propyl, $n$-butyl, $i$-butyl, $t$-butyl, etc. To this aim, the appropriate insertion patterns simply need to be added and the recursion formulae of Equations (22) and (31) need to be modified correspondingly, together with the initial values. The pattern insertion method also allows calculating other properties of lateral chains recursively. For examples of this, the reader is referred to Valéry et al. (2007).

Compared to the structural class methodology, the lateral chain decomposition approach is slightly more complex for low branching numbers but it is much more efficient. Indeed, the use of recursion formulae avoids accounting for exceptions. This allows calculating the various series that constitute the lumping coefficients from the lowest carbon number to the highest carbon number, while special treatment is needed for low carbon numbers with the structural class approach. Moreover, the lateral chain decomposition method allows for a much easier extension to high branching numbers. As mentioned above, the results of both methods are strictly equivalent, since they use the same hypotheses.

\section{MODEL VS EXPERIMENTATION}

\subsection{Experimentation}

Experiments were performed in an isothermal tubular fixed bed reactor in upflow mode at a total pressure of 150 bar and temperature of $375^{\circ} \mathrm{C}$. The reactor was loaded with $80 \mathrm{~g}$ of an industrial NiMo on a Y-zeolite based catalyst. The catalyst was sulfided with a hydrogenated LCO to which $2 \mathrm{wt} \%$ of DiMethylDiSulfide (DMDS) and $0.1 \mathrm{wt} \%$ of aniline was added. The pretreating feed was injected at a LHSV of $1 \mathrm{~h}^{-1}$, with a volumetric $\mathrm{H}_{2} / \mathrm{HC}$ ratio of $1000 \mathrm{Nl} / \mathrm{l}$. The temperature was progressively increased to $350^{\circ} \mathrm{C}$. Sulfiding was continued for at least $12 \mathrm{~h}$ and until the $\mathrm{H}_{2} \mathrm{~S}$ composition in the effluent remained constant. Before carrying out the kinetic experiments, a line-out period of $150 \mathrm{~h}$ at $375^{\circ} \mathrm{C}$ with the sulfiding feed was applied in order to reach a stable catalyst performance.

As primary feedstock, pure $n$-hexadecane $\left(\mathrm{C}_{16} \mathrm{H}_{34}\right)$ was chosen (purity $>99 \%$ ) to which DMDS and $n$-butylamine were added to maintain the catalyst in a sulfided state and under industrial conditions with respect to the presence of $\mathrm{H}_{2} \mathrm{~S}$ and $\mathrm{NH}_{3}$. As $n$-hexadecane freezes at $18^{\circ} \mathrm{C}$, all equipment and lines in pilot plant were maintained above $25^{\circ} \mathrm{C}$. Kinetic data were collected at various LHSV ranging from $0.15 \mathrm{~h}^{-1}$ to $1 \mathrm{~h}^{-1}$. The partial pressure of $\mathrm{H}_{2} \mathrm{~S}$ and of $\mathrm{NH}_{3}$ amounted approximately to 1 bar and 0.1 bar respectively. The reactor effluent was separated in a flash drum at ambient 
temperature. The gas fraction was analysed on-line, while the liquid effluent was sampled and analysed on a GC equipped with a PONA column. For components with 8 carbon atoms or less, the GC method allows to obtain the full molecular detail. For components with more than 8 carbon atoms, the available analytic detail allows to distinguish components by carbon numbers and degree of branching, which corresponds to the lumps of the above a posteriori relumped models.

To validate the single event kinetic model developed for $n$-hexadecane, additional experiments were carried out with a Fischer-Tropsch wax, a mixture of heavy paraffins with 20 to 33 carbon atoms (Tab. 3). This Fischer-Tropsch wax was also separated by distillation into 4 smaller boiling point ranges. Again, DMDS and aniline were added to all these feeds to maintain the catalyst in a sulfided state and under industrial conditions with respect to the presence of $\mathrm{H}_{2} \mathrm{~S}$ and $\mathrm{NH}_{3}$. During these experiments, all equipment and lines in pilot plant were maintained above $60^{\circ} \mathrm{C}$. The experiments were carried out under the same conditions and kinetic data were collected at various LHSV ranging from $0.15 \mathrm{~h}^{-1}$ to $1 \mathrm{~h}^{-1}$.

TABLE 3

Composition of the $\mathrm{C}_{19}-\mathrm{C}_{33}$ Fischer-Tropsch wax (in mol\%)

\begin{tabular}{|c|c|c|c|}
\hline Carbon number & $n$-Paraffins & Iso-paraffins & Total \\
\hline 19 & 0.15 & 0 & 0.15 \\
\hline 20 & 0.86 & 0 & 0.86 \\
\hline 21 & 2.32 & 0 & 2.32 \\
\hline 22 & 4.70 & 0.03 & 4.73 \\
\hline 23 & 8.10 & 0.16 & 8.26 \\
\hline 24 & 11.79 & 0.52 & 12.31 \\
\hline 25 & 12.96 & 0.96 & 13.92 \\
\hline 26 & 12.68 & 1.58 & 14.26 \\
\hline 27 & 10.39 & 2.02 & 12.41 \\
\hline 28 & 8.12 & 2.01 & 10.13 \\
\hline 29 & 6.46 & 1.86 & 8.32 \\
\hline 30 & 4.11 & 1.55 & 5.66 \\
\hline 31 & 2.56 & 1.31 & 3.87 \\
\hline 32 & 1.33 & 0.60 & 1.93 \\
\hline 33 & 0.60 & 0.27 & 0.87 \\
\hline Total & 87.13 & 12.87 & 100 \\
\hline
\end{tabular}

Finally, experiments with squalane $(2,6,10,15,19,23$ hexamethyltetracosane; $\mathrm{C}_{30} \mathrm{H}_{62} ; 99 \%$ purity; Haltermann Chemicals) were also carried out in order to look at the effect of the degree of branching on the model predictions. As before, DMDS and a nitrogen-containing compound (either $n$-butyl amine or aniline) were added to the feed in order to maintain the catalyst in a sulfided state and under industrial conditions with respect to the presence of $\mathrm{H}_{2} \mathrm{~S}$ and $\mathrm{NH}_{3}$. Again, the experiments were carried out under the same conditions and kinetic data were collected at various LHSV ranging from $0.5 \mathrm{~h}^{-1}$ to $1.53 \mathrm{~h}^{-1}$ (Valéry et al., 2007).

\subsection{Parameter Identification}

The single event kinetic model was incorporated in a plug flow reactor model. As gas and liquid were supposed to be at equilibrium inside the reactor, the compositions of the two phases were calculated by means of a Grayson-Streed flash module in each of the differential elements of the reactor. This then leads to a system of Ordinary Differential Equations (ODE):

$$
\frac{d F_{i}}{d W}=R_{i}
$$

These equations were reorganized and integrated according to space time, $W / F_{t o t}^{0}$, where $W$ is the weight of catalyst inside the reactor and $F_{\text {tot }}^{0}$ the total molar flow at the inlet of the reactor. The resulting differential equations of the reactor were solved with LSODE (Hindmarsch, 1980, 1983).

Parameters were identified by minimizing the sum of the squared errors $\sum_{i=1}^{\text {nobs }}\left(y_{i}-\hat{y}_{i}\right)^{2}$, initially with a simulated annealing algorithm (Goffe et al., 1994) to screen the response surface, while a Levenberg-Marquardt algorithm (Levenberg, 1944; Marquardt, 1963) was used to obtain the final parameter estimates. The parameters were estimated based on 160 observations of the various responses obtained during the experiments with $n$-hexadecane. As the model appeared to be insensitive to the values of the protonation/ deprotonation equilibrium constants for secondary and tertiary carbenium ions, these equilibrium constants and reaction rate coefficients were re-parameterized into composite reaction rate coefficients as follows:

$$
k_{\text {reac }}^{*}(m ; u)=\tilde{K}_{\mathrm{Pr}}\left(m ; O_{\text {ref }}\right) \cdot \tilde{k}_{\text {reac }}(m ; u)
$$

During the identification of the 6 remaining parameters, it also appeared that the composite parameters $k_{p c p}^{*}(s ; t)$ and $k_{p c p}^{*}(t ; t)$ were highly correlated. To solve this, it was arbitrary chosen not to estimate $k_{p c p}^{*}(t ; t)$ and its value was put to zero. This led to the final parameter shown in Table 4. The secondary-tertiary cracking rate coefficient $k_{c r}^{*}(s ; t)$ was found to be extremely low. Moreover, according to the statistical analysis, this parameter was found to be statistically non-significant. This is most certainly due to coupling effects or to indiscernability between $(s, t)$ and $(t, s)$ cracking on the lumps. Hence, the composite rate coefficient $k_{c r}^{*}(s ; t)$ was therefore put to zero. 
TABLE 4

Final parameter values for the hydrocracking of $n$-hexadecane

\begin{tabular}{c|c|c|c}
\hline Parameters & Best value & Standard deviation & $t$-Value \\
\hline$k_{p c p}^{*}(s, s)$ & $3.08 \times 10^{2}$ & $0.03 \times 10^{2}$ & 99.3 \\
\hline$k_{p c p}^{*}(s, t)$ & $6.07 \times 10^{3}$ & $0.22 \times 10^{3}$ & 27.6 \\
\hline$k_{c r}^{*}(s, s)$ & $1.89 \times 10^{3}$ & $0.17 \times 10^{3}$ & 11.1 \\
\hline$k_{c r}^{*}(s, t)$ & $2.73 \times 10^{-3}$ & $8.70 \times 10^{3}$ & 0 \\
\hline$k_{c r}^{*}(t, s)$ & $2.28 \times 10^{4}$ & $0.98 \times 10^{4}$ & 2.3 \\
\hline$k_{c r}^{*}(t, t)$ & $9.07 \times 10^{5}$ & $1.30 \times 10^{5}$ & 7.0 \\
\hline
\end{tabular}

With the final parameters, the model behaves quite satisfactorily. The overall conversion of $n$-hexadecane is well predicted, as is the prediction of total amount of isomerized products and of cracked products (Fig. 8). Within the isomerized products of the $n$-hexadecane feed, the evolution of the main simulated lumps (normal, mono- and multibranched hexadecanes) is relatively close to the experimental trend (Fig. 9). With respect to cracking, the relumped single event model retains enough detail to predict a detailed distribution of the cracked products. As shown in Figure 10 for the linear paraffins, both the orders of magnitude and the trends of the product distribution of the cracked products are quite well predicted, especially when taking into account that the model only contains 6 parameters.

To validate the model, the values of the parameters obtained from the experiments on $n$-hexadecane were used to simulate the experiments obtained on the Fischer-Tropsch wax and on its sub-fractions obtained by distillation. As these feeds are composed of paraffins with 20 to 33 carbon atoms, this comparison allows to directly evaluate the extrapolation with respect to the number of carbon atoms. Figure 11 compares the predicted yields for the linear $\mathrm{C}_{20+}$ paraffins $\left(n \mathrm{C}_{20+}\right)$, for

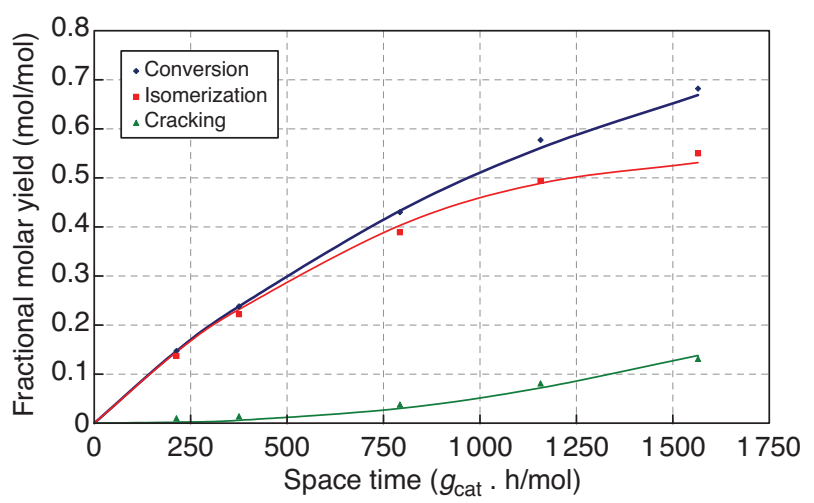

Figure 8

Conversion, isomerization and cracking of $n$-hexadecane as a function of space time (points: experimental, lines: simulated).

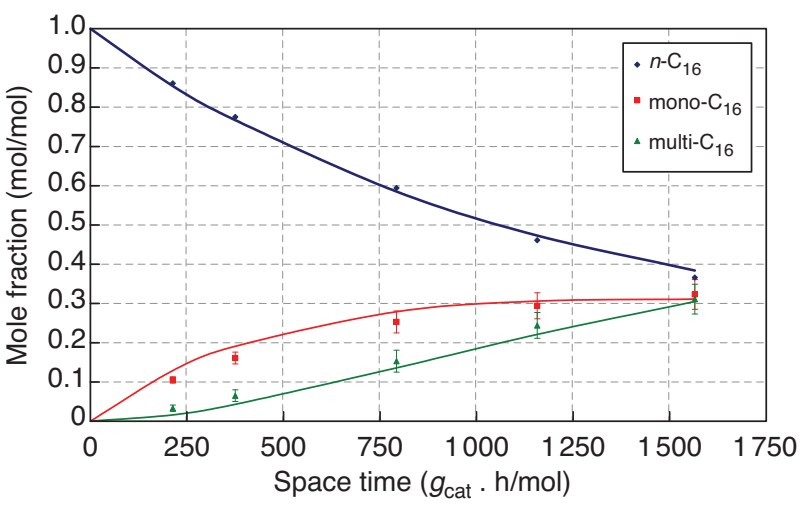

Figure 9

Composition of the $\mathrm{C}_{16}$ fraction as a function of space time (points: experimental, lines: simulated).

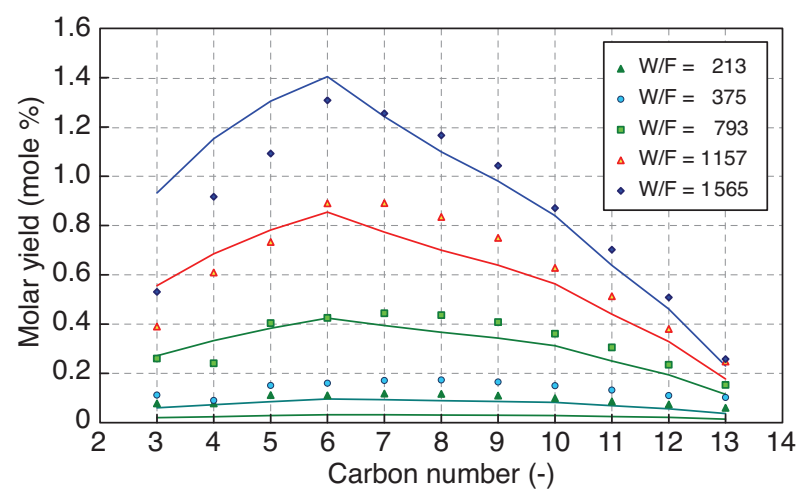

Figure 10

Experimental and model predicted distribution of lower carbon number $n$-paraffins for $n$-hexadecane hydrocracking (points: experimental, lines: simulated).

the isomerized $\mathrm{C}_{20+}$ paraffins $\left(i \mathrm{C}_{20+}\right)$ and for the cracked products to the experimental data obtained during cracking of Fischer-Tropsch wax. It can be noticed that the decrease of the $n \mathrm{C}_{20+}$ paraffins is well predicted, indicating that the value of the $k_{p c p}^{*}(s ; t)$ rate coefficient is well estimated and allows to correctly extrapolate to higher carbon numbers. However, the yield of isomerized $\mathrm{C}_{20+}$ paraffins is somewhat overestimated at low space times, while the yield of cracked products with less than 20 carbon atoms is slightly underestimated. This indicates that the rate of cracking is underestimated to some extent when the degree of branching is relatively low. At high space times, the predicted yield of cracked products is higher than its experimental yield, indicating that the reaction rate is too high when the degree of branching is high. For the sub-fractions obtained by distillation of the Fischer-Tropsch wax, the comparison model-experiments of the yields of $n \mathrm{C}_{20+}, i \mathrm{C}_{20+}$ and cracked products is shown as a parity plot in 


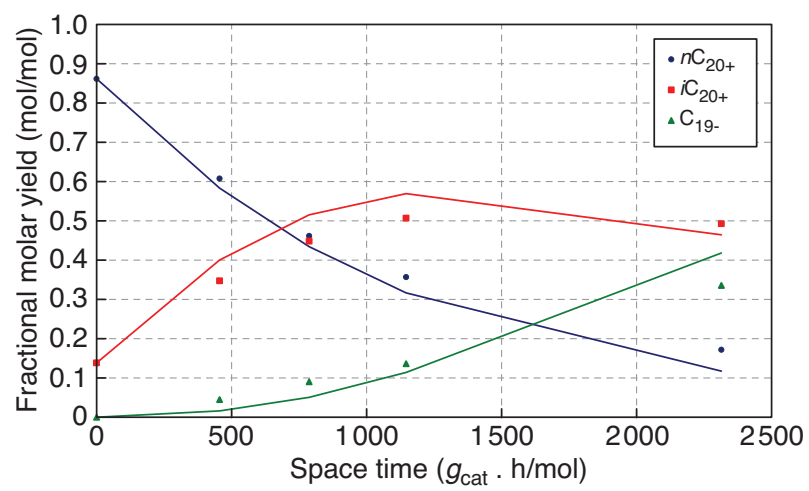

Figure 11

Yields of $n \mathrm{C}_{20+}, i \mathrm{C}_{20+}$ and cracked products during cracking of the Fischer-Tropsch wax as a function of space time (points: experimental, lines: simulated).

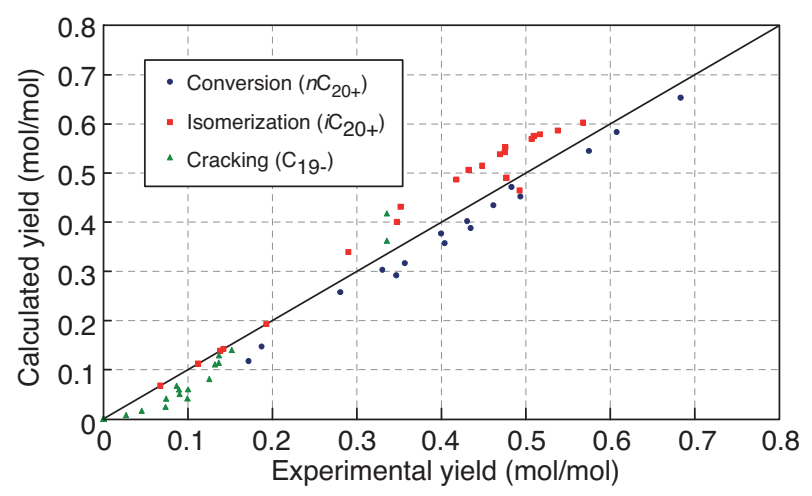

Figure 12

Parity plot for the fractional molar yields of $n \mathrm{C}_{20+}, i \mathrm{C}_{20+}$ and cracked products during cracking of the sub-fractions of the Fischer-Tropsch wax.

Figure 12. The same conclusions can be drawn: the isomerization of the $n \mathrm{C}_{20+}$ paraffins is quite well predicted, the yield of the $i \mathrm{C}_{20+}$ paraffins is slightly overestimated, while yield of the cracked products is somewhat underestimated. The predicted distribution of cracked products is compared to the experimental product distribution in Figure 13 at a conversion of $68 \mathrm{wt} \%$ of the $n \mathrm{C}_{20+}$ paraffins of the $\mathrm{C}_{25} \mathrm{C}_{31}$ sub-fraction of the Fischer-Tropsch wax. Looking at the feed, a nearly perfect agreement is observed for the disappearance of the linear paraffins of the $\mathrm{C}_{25}-\mathrm{C}_{31}$ feed, while the heaviest isoparaffins $\left(\mathrm{C}_{27}-\mathrm{C}_{30}\right)$ are somewhat overestimated. For the cracked products, the model-predicted distribution profile of lower molecular weight $n$-paraffins $\left(\mathrm{C}_{3}-\mathrm{C}_{24}\right)$ has the same profile as the experimentally observed profile, although the absolute values are somewhat lower. For lower molecular weight isoparaffins $\left(\mathrm{C}_{4}-\mathrm{C}_{24}\right)$, both the distribution and the absolute values are very well predicted. In conclusion, a good

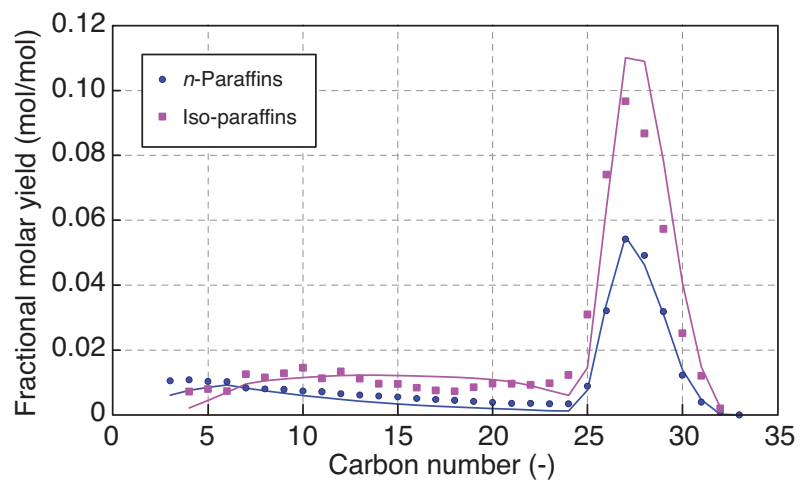

Figure 13

Distribution of the normal and iso-paraffins at a conversion of $68 \mathrm{wt} \%$ of the $n \mathrm{C}_{20+}$ paraffins of the $\mathrm{C}_{25}-\mathrm{C}_{31}$ sub-fraction of the Fischer-Tropsch wax (points: experimental, lines: simulated).

overall agreement is obtained when extrapolating the single event kinetic model from a low carbon number $\left(\mathrm{C}_{16}\right)$ to higher carbon numbers $\left(\mathrm{C}_{20}\right.$ to $\left.\mathrm{C}_{33}\right)$ without adjusting any of the parameters.

To further validate the model, the values of the kinetic parameters obtained from the experiments on $n$-hexadecane were also used to simulate the experiments with squalane as feed (Valéry et al., 2007). As squalane is an isoparaffin of 30 carbon atoms with 6 methyl side chains, this feed allows evaluating at the same time an extrapolation with respect to the number of carbon atoms and with respect to the number of side chains. While the experimentally observed squalane conversions varied between $26 \%$ and $71 \%$ with space time, the model predicted conversions varied between $83 \%$ and $99 \%$ for the same range. The model therefore largely overpredicts the rate of disappearance of squalane. To correctly predict the conversion, all rate coefficients had to be reduced by a factor of 4.74 . With this reduced catalyst activity, the model correctly predicts both the distribution and the amount of the cracked products as a function of carbon number (Fig. 14). In the experiments described by Valéry et al. (2007), the average degree of branching as a function of carbon number was also experimentally determined. Figure 15 illustrates that the model is equally able to predict the evolution of the degree of branching of the cracked products as a function of carbon number. As a conclusion, although the catalyst activity was largely overestimated for the cracking of squalane, the product distribution and the degree of branching of the cracked products were well predicted at the experimental conversion.

Several explanations can be proposed for the high reactivity of the highly branched squalane in the single event kinetic model. First of all, the single event kinetic model contains an 


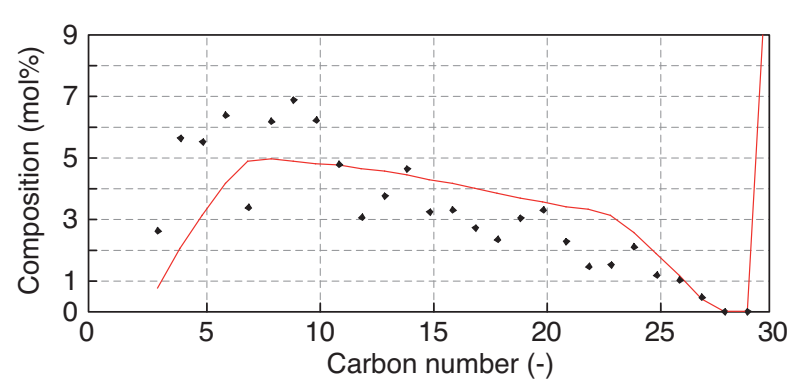

Figure 14

Distribution by carbon number of the cracked products at a conversion of $71 \mathrm{wt} \%$ of the squalane feed.

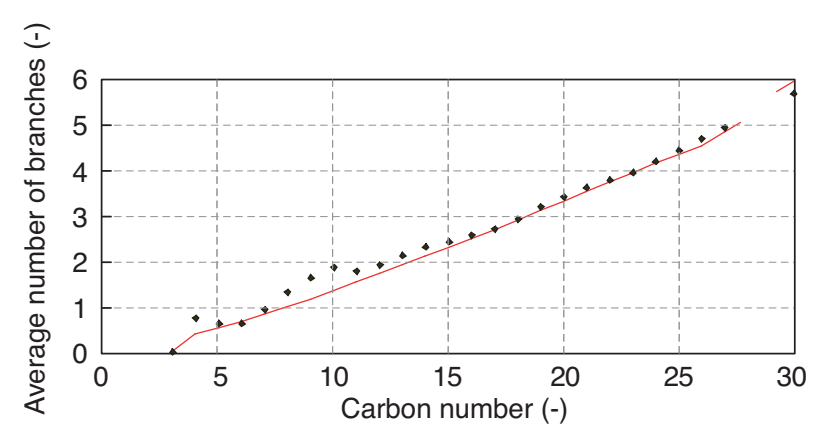

Figure 15

Evolution of the degree of branching of the cracked products as a function of carbon number at a conversion of $71 \mathrm{wt} \%$ of the squalane feed.

inhibition term that accounts for physical adsorption in the zeolite. In this inhibition term, the physical adsorption coefficient of a lump is considered to be the same for all paraffins with more 16 carbon atoms. As shown by the validation on the Fischer-Tropsch wax, this hypothesis seems to be quite adequate. However, the physical adsorption coefficient is also considered to be independent of the degree of branching. This hypothesis may therefore be at the basis of the too high reactivity of squalane with respect to linear long-chain paraffins. An other explanation of the overprediction of the reactivity of squalane may be linked to the chemisorption of the carbenium ions, as the proposed kinetic model does not contain an inhibition term due to chemisorption on acid sites. Indeed, previous literature studies (Svoboda et al., 1995; Martens and Froment, 1999; Martens and Marin, 2001) have shown that the total concentration of carbenium ions could be neglected compared to the total concentration of acid sites. However, these observations were based on hydrocracking experiments on $n-\mathrm{C}_{8}$ to $n-\mathrm{C}_{12}$ paraffins and on mixtures of $n-\mathrm{C}_{8}$ with 10 mole\% of branched $\mathrm{C}_{8}$ paraffins. This may no longer be the case with very highly branched isoparaffins such as squalane. Indeed, squalane has 6 tertiary carbon atoms that may allow for a much higher chemisorption on the acid phase, hence reducing the apparent catalyst activity. In such a case, the chemisorption of highly branched isoparaffins can no longer be neglected.

Mitsios et al. (2009) also developed a single event kinetic model for hydroisomerization and hydrocracking, which was applied to $n$-hexadecane, a $\mathrm{C}_{20}-\mathrm{C}_{30}$ wax and squalane on an amorphous $\mathrm{Pt} / \mathrm{SiO}_{2} \bullet \mathrm{Al}_{2} \mathrm{O}_{3}$ catalyst. In their single event kinetic model, they did not account for physisorption, as no external or internal limitations were considered to be present in this macroporous non-zeolitic catalyst. However, their model accounted for the chemisorption of the carbenium ions on acid sites. When extrapolating this model, which does not account for physisorption while accounting for chemisorption, from $n$-hexadecane to the $\mathrm{C}_{20}-\mathrm{C}_{30}$ wax and to squalane, the model predicted the correct order of magnitude for the conversion, and for the isomerization and cracking selectivities on all feeds.

\section{CONCLUSION}

In order to apply the single event methodology to acid-catalyzed reactions with high carbon number hydrocarbon fractions, huge calculation times are required for the explicit generation of the complete exhaustive list of molecules and single events reactions. Although this approach is straightforward, it requires generating all elementary steps individually and storing this entire network. In the literature, alternative approaches have been developed that directly calculate the lumping coefficients of a posteriori relumped single event reaction networks. The above-described lateral chain decomposition strategy divides the various components (molecules, intermediates and activated complexes) into lateral chains and activated zones. Detailed inspection of these various parts allowed deriving a set of recursive formulae that calculate the various structural and thermodynamic properties that are needed to determine the lumping coefficients. It should be stressed that the lateral chain decomposition technique is exactly equivalent to the original calculation method based on the explicitly generated reaction network, as long as Benson's group contribution method is used to obtain the necessary thermodynamic data in both approaches. The advantage of these recursive formulae resides in the fact that application of the single event modelling methodology to very large reaction networks and very high degrees of branching is highly simplified, both in comparison to the explicit generation of the entire reaction network and to the structural class approach.

A kinetic model for hydroisomerization and hydrocracking of $n$-hexadecane was developed using this lateral chain decomposition approach. After identification of the 6 remaining kinetic parameters, the kinetic model was confronted to the experimental data and a good agreement between the predicted and measured product distributions was obtained, both with respect to isomerization and hydrocracking of $n$-hexadecane. 
To validate the kinetic model, hydrocracking experiments were carried out on various fractions of a $\mathrm{C}_{20}-\mathrm{C}_{33}$ FischerTropsch wax. Without adjusting any of the parameters, the single event kinetic model correctly predicts the isomerization of the linear $\mathrm{C}_{20+}$ paraffins. Although the yield of cracked products is slightly underestimated at low conversion at the expense of the isomerized $\mathrm{C}_{20+}$ paraffins, their product distribution as a function of carbon number is very well predicted. In conclusion, a good overall agreement is obtained when extrapolating the single event kinetic model from a low carbon number $\left(\mathrm{C}_{16}\right)$ to higher carbon numbers $\left(\mathrm{C}_{20}\right.$ to $\left.\mathrm{C}_{33}\right)$.

Extrapolating the kinetic model with respect to the number of carbon atoms and with respect to the number of side chains at the same time was also attempted. Confronting the model with the squalane experiments (Valéry et al., 2007) showed that the rate of disappearance of squalane was largely overpredicted. At the experimental conversion, the selectivity towards cracked products, the cracked product distribution and their degree of branching were well predicted, however. Several explanations can be proposed for the discrepancies between the model and the experiments, as these seem to indicate that the simplifying hypotheses concerning physisorption and/or chemisorption are no longer valid for highly branched paraffins.

The lateral chain decomposition method described in this work is quite flexible. Indeed, it can easily be extended to more general lateral chains, as it is straightforward to introduce new insertion patterns, to adapt the recursion formulae accordingly, and to develop recursion formulae for new lateral chain properties.

\section{REFERENCES}

Al Wahabi S.M., Froment G.F. (2004) Single Event Kinetic Modeling of the Methanol-to-Olefins Process on SAPO-34, Ind. Eng. Chem. Res. 43, 5098-5111.

Baltanas M.A., Vansina H., Froment G.F. (1983) Hydroisomerization and Hydrocracking V - Kinetic Analysis of Rate Data for N-Octane, Ind. Eng. Chem. Prod. Res. Dev. 22, 531-539.

Baltanas M.A. Froment G.F. (1985) Computer generation of reaction networks and calculation of product distributions in the hydroisomerization and hydrocracking of paraffins on Pt-containing bifunctional catalysts, Comput. Chem. Eng. 9, 71-81.

Baltanas M.A., Van Raemdonck K.K., Froment G.F., Mohedas S.R. (1989) Fundamental kinetic modeling of hydroisomerization and hydrocracking on noble-metal-loaded faujasites. 1. Rate parameters for hydroisomerization, Ind. Eng. Chem. Res. 28, 899-910.

Beirnaert H.C., Alleman J.R., Marin G.B. (2001) A Fundamental Kinetic Model for the Catalytic Cracking of Alkanes on a USY Zeolite in the Presence of Coke Formation, Ind. Eng. Chem. Res. 40, 5, 1337-1347.

Benson S.W., Cruickshank F.R., Golden D.M., Haugen G.R., O'Neal H.E., Rodgers A.S., Shaw R., Walsch R. (1969) Additivity rules for estimation of thermodynamical properties, Chem. Rev. 69 , 279-324.

Benson S.W. (1976) Thermochemical kinetics, second edition, Wiley \& Sons, New York.
Chavarría-Hernández J.C., Ramírez J., Gonzalez H., Baltanas M.A. (2004) Modelling of $n$-hexadecane Hydroisomerization and Hydrocracking Reactions on a Mo/H Beta-Alumina Bi-Functional Catalyst Using the Single Event Concept, Catal. Today 98, 1-2, 235-242.

Chavarría-Hernández J.C., Ramírez J., Baltanas M.A. (2008) Single-event-lumped-parameter hybrid (SELPH) model for nonideal hydrocracking of n-octane, Catal. Today 130, 2-4, 455-461.

Chavarría-Hernández J.C., Ramírez J. (2009) Modeling Ideal and Nonideal Hydrocracking of Paraffins Using the Single-Event Lumped Parameter Hybrid (SELPH) Model, Ind. Eng. Chem. Res. 48, 3, 1203-1207.

Choudhury I.R., Thybaut J.W., Balasubramanian P., Denayer J.F.M., Martens J.A., Marin G.B. (2010) Synergy between shape selective and non-shape selective bifunctional zeolites modelled via the Single-Event MicroKinetic (SEMK) methodology, Chem. Eng. Sci. 65, 174-178.

Cochegrue H., Gauthier P., Verstraete J.J., Surla K., Guillaume D., Galtier P., Barbier J. (2011) Reduction of single event kinetic models by rigorous relumping: application to the catalytic reforming, Oil Gas Sci.Technol., 66, 367-397.

Debrabandere B., Froment G.F. (1997) Influence of the Hydrocarbon Chain Length on the Kinetics of the Hydroisomerization and Hydrocracking of $n$-Paraffins, in Hydrotreatment and Hydrocracking of Oil Fractions, Elsevier Science Publ. BV, Amsterdam, 106, pp. 379-389.

Denayer J.F., Baron G.V. (1998) Chromatographic study of adsorption of $n$-alkanes on zeolites at high temperatures, J. Phys. Chem. B 102, 3077-3081.

Dewachtere N.V., Santaella F., Froment G.F. (1999) Application of a single-event kinetic model in the simulation of an industrial riser reactor for the catalytic cracking of vacuum gas oil, Chem. Eng. Sci. 54, 15-16, 3653-3660.

Feng W., Vynckier E., Froment G.F. (1993) Single-event kinetics of catalytic cracking, Ind. Eng. Chem. Res. 32, 12, 2997-3005.

Froment G.F. (1999) Kinetic modeling of acid-catalyzed oil refining processes, Catal. Today 52, 153-163.

Froment G.F. (2005) Single Event Kinetic Modeling of Complex Catalytic Processes, Catal. Rev. 47, 83-124.

Goffe W.L., Ferrier G.D., Rogers J. (1994) Global Optimization of Statistical Functions with Simulated Annealing, J. Econom. 60, 1-2, 65-99.

Guillaume D. (2006) Network Generation of Oligomerization Reactions: Principles, Ind. Eng. Chem. Res. 45, 13, 4554-4557.

Guillaume D., Surla K., Galtier P. (2003a) From Single Events theory to molecular kinetics - application to industrial process modeling, Chem. Eng. Sci. 58, 21, 4861-4869.

Guillaume D., Valéry E., Surla K., Galtier P., Verstraete J., Schweich D. (2003b) Single Events Modeling - extension to large networks, Communication at ECCE4, Grenade, Espagne

Hindmarsch A.C. (1980) LSODE and LSODI, Two New Initial Value Ordinary Differential Equation Solvers, A.C.M., Signum Newsl. 15, 4, 19-21.

Hindmarsch A.C. (1983) ODEPACK, a systematized collection of ODE solvers, in Scientific Computing, Stepleman R.S. et al. (eds), IMACS, North-Holland, Amsterdam, pp. 55-64.

Kumar H., Froment G.F. (2007a) A generalized mechanistic kinetic model for the hydroisomerization and hydrocracking of long-chain paraffins, Ind. Eng. Chem. Res. 46, 12, 4075-4090.

Kumar H., Froment G.F. (2007b) Mechanistic Kinetic Modeling of the Hydrocracking of Complex Feedstocks, such as Vacuum Gas Oils, Ind. Eng. Chem. Res. 46, 18, 5881-5897. 
Laxmi Narasimhan C.S., Thybaut J.W., Marin G.B., Martens J.A., Denayer J.F., Baron G.V. (2003a) Pore mouth physisorption of alkanes on ZSM-22: estimation of physisorption enthalpies and entropies by additivity method, J. Catal. 218, 1, 135-147.

Laxmi Narasimhan C.S., Thybaut J.W., Marin G.B., Jacobs P.A., Martens J.A., Denayer J.F., Baron G.V. (2003b) Kinetic modeling of pore mouth catalysis in the hydroconversion of $n$-octane on $\mathrm{Pt}-\mathrm{H}-$ ZSM-22, J. Catal. 220, 2, 399-413.

Laxmi Narasimhan C.S., Thybaut J.W., Marin G.B., Denayer J.F., Baron G.V., Martens J.A., Jacobs P.A. (2004) Relumped singleevent microkinetic model for alkane hydrocracking on shape-selective catalysts: catalysis on ZSM-22 pore mouths, bridge acid sites and micropores, Chem. Eng. Sci. 59, 22-23, 4765-4772.

Laxmi Narasimhan C.S., Thybaut J.W., Martens J.A., Jacobs P.A., Denayer J.F., Marin G.B. (2006) A unified single-event microkinetic model for alkane hydroconversion in different aggregation states on Pt/H-USY-zeolites, J. Phys. Chem. B 110, 13, 6750-6758.

Laxmi Narasimhan C.S., Thybaut J.W., Denayer J.F., Baron G.V., Jacobs P.A., Martens J.A., Marin G.B. (2007) Aggregation state effects in shape-selective hydroconversion, Ind. Eng. Chem. Res. 46, 25, 8710-8721.

Levenberg K. (1944) A Method for the Solution of Certain Problems in Least Squares, Quart. Appl. Math. 2, 2, 164-168.

Marquardt D. (1963) An Algorithm for Least-Squares Estimation of Nonlinear Parameters, J. Soc. Ind. Appl. Math . 11, 2, 431-441.

Martens G.G. (2000) Hydrocracking on Pt/USY zeolites: Fundamental kinetic modelling and industrial reactor simulation, PhD Thesis, University of Ghent.

Martens G.G., Froment G.F. (1999) Kinetic modeling of paraffins hydrocracking based upon elementary steps and the single event concept, in Reaction kinetics and the development of catalytic processes, Froment G.F., Waugh K.C. (eds), Elsevier Science BV, Stud. Surface Sci. Catal. 122, 333-340.

Martens G.G., Marin G.B., Martens J.A., Jacobs P.A., Baron G.V. (2000) A fundamental kinetic model for hydrocracking of C8 to C12 alkanes on Pt/US-Y zeolites, J. Catal. 195, 2, 253-267.

Martens G.G., Marin G.B. (2001) Kinetics for hydrocracking based on structural classes: Model development and application, AIChE J. 47, 7, 1607-1622.

Martens G.G., Thybaut J.W., Marin G.B. (2001) Single event rate parameters for hydrocracking of cycloalkanes on Pt/US-Y zeolites, Ind. Eng. Chem. Res. 40, 1832-1844.

Martinis J.M., Froment G.F. (2006) Alkylation on Solid Acids. Part 2. Single-Event Kinetic Modeling, Ind. Eng. Chem. Res. 45, 954.

Mitsios M., Guillaume D., Galtier P., Schweich D. (2009) SingleEvent Microkinetic Model for Long-Chain Paraffin Hydrocracking and Hydroisomerization on an Amorphous $\mathrm{Pt} / \mathrm{SiO}_{2}-\mathrm{Al}_{2} \mathrm{O}_{3}$ Catalyst, Ind. Eng. Chem. Res. 48, 3284-3292.

Moustafa T., Froment G.F. (2003) Kinetic Modeling of Coke Formation and Deactivation in the Catalytic Cracking of Vacuum Gas Oil, Ind. Eng. Chem. Res. 42, 1, 14-25

Park T.-Y., Froment G.F. (2001a) Kinetic Modeling of the MTO Process - I. Model Formulation, Ind. Eng. Chem. Res. 40, 41724186.

Park T.-Y., Froment G.F. (2001b) Kinetic Modeling of the MTO Process - II. Experimental Results, Model Discrimination and Parameter Estimation, Ind. Eng. Chem. Res. 40, 4187-4196.

Park T.-Y., Froment G.F. (2004) Analysis of fundamental reaction rates in the methanol-to-olefins process on ZSM- 5 as a basis for reactor design and operation, Ind. Eng. Chem. Res. 43, 3, 682-689.

Quintana-Solórzano R., Thybaut J.W., Marin G.B., Lødeng R., Holmen A. (2005) Single-Event MicroKinetics for coke formation in catalytic cracking, Catal. Today 107, 8, 619-629.
Quintana-Solórzano R., Thybaut J.W., Marin G.B. (2007a) A single-event microkinetic analysis of the catalytic cracking of (cyclo)alkanes on an equilibrium catalyst in the absence of coke formation, Chem. Eng. Sci. 62, 18-20, 5033-5038

Quintana-Solórzano R., Thybaut J.W., Galtier P., Marin G.B. (2007b) Single-Event MicroKinetics for coke formation during the catalytic cracking of (cyclo)alkane/1-octene mixtures, Catal. Today 127, 1, 17-30.

Quintana-Solórzano R., Thybaut J.W., Galtier P., Marin G.B. (2010) Simulation of an industrial riser for catalytic cracking in the presence of coking using Single-Event MicroKinetics, Catal. Today 150, 319-331.

Schweitzer J.M., Galtier P., Schweich D. (1999) A single events kinetics model for hydrocracking of paraffins in a three phase reactor, Chem. Eng. Sci. 54, 2441-2452.

Shahrouzi J.R., Guillaume D., Rouchon P., Da Costa P. (2008) Stochastic Simulation and Single Events Kinetic Modeling: Application to Olefin Oligomerization, Ind. Eng. Chem. Res. 47, 13, 4308-4316

Sotelo-Boyás R., Froment G.F. (2009) Fundamental Kinetic Modeling of Catalytic Reforming, Ind. Eng. Chem. Res. 48, 3, 1107-1119

Steijns M., Froment G.F., Jacobs P.A., Uytterhoeven J., Weitkamp J. (1981) Hydroisomerization and Hydrocracking II - Product Distributions, Ind. Eng. Chem. Prod.Res. Dev. 20, 654-660.

Steijns M., Froment G.F. (1981) Hydroisomerization and Hydrocracking. 3. Kinetic-Analysis of Rate Data for NormalDecane and Normal-Dodecane, Ind. Eng. Chem. Prod. Res. Dev. 20 4, 660-668.

Surla K., Vleeming H., Guillaume D., Galtier P. (2004) A single events kinetic model: $n$-butane isomerization, Chem. Eng. Sci. 59, 22-23, 4773-4779.

Surla K., Guillaume D., Verstraete J., Galtier P., Gauthier P., Leroy H. (2011) Réduction of single event kinetic models by rigorous relumping: application to the catalytic reforming, Oil Gas Sci. Technol., 66, 343-365.

Svoboda G.D., Vynckier E., Debrabandere B. Froment G.F. (1995) Single event rate parameters for paraffin hydrocracking on a Pt/USY zeolite, Ind.Eng. Chem. Res. 34, 3793-3800.

Thybaut J.W., Marin G.B., Baron G.V., Jacobs P.A., Martens J.A. (2001) Alkene protonation enthalpy determination from fundamental kinetic modeling of alkane hydroconversion on $\mathrm{Pt} / \mathrm{H}-(\mathrm{US}) \mathrm{Y}-$ Zeolite, J. Catal. 202, 324-339.

Thybaut J.W., Marin G.B. (2003) Kinetic Modeling of the Conversion of Complex Hydrocarbon Feedstocks by Acid Catalysis, Chem. Eng. Technol. 26, 4, 509-514.

Thybaut J.W., Choudhury I.R., Denayer J.F., Baron G.V., Jacobs P.A., Martens J.A., Marin G.B. (2009) Design of optimum zeolite pore system for central hydrocracking of long-chain $n$-alkanes based on a Single-Event MicroKinetic model, Topics Catal. 52, 9, 12511260 .

Valéry E. (2000) Modélisation cinétique des réactions catalytiques d'hydrocraquage par la théorie des événements constitutifs, Internal IFP Report.

Valéry E. (2002) Application de la théorie des événements constitutifs à l'hydrocraquage de paraffines lourdes, $P h D$ Thesis, Institut Français du Pétrole.

Valéry E., Guillaume D., Surla K., Galtier P., Verstraete J., Schweich D. (2007) Kinetic modeling of acid catalyzed hydrocracking of heavy molecules: application to squalane, Ind. Eng. Chem. Res. 46, 14, 4755-4763. 
Vansina H., Baltanas M.A., Froment G.F. (1983) Hydroisomerization and Hydrocracking. 4. Product Distribution from $n$-Octane and 2,2,4-Trimethylpentane, Ind. Eng. Chem. Prod. Res. Dev. 22, 4,526 .

Vynckier E., Froment G.F. (1991) Modeling of the kinetics of complex processes upon elementary steps, in Kinetic and thermodynamic lumping of multicomponent mixtures, Starita G., Sandler S.I. (eds), Elsevier Science Publishers B.V., Amsterdam, The Netherlands, pp. 131-161.
Wei J., Kuo J.C.W. (1969) Lumping Analysis in Monomolecular Reaction Systems. Analysis of the Exactly Lumpable System, Ind. Eng. Chem. Fundam. 8, 114-123.

Final manuscript received in April 2011

Published online in June 2011 fax. +33147527096 , or revueogst@ifpen.fr. 